Rieko Sakai · Claudia Elfgang · Rolf Vogel •

Klaus Willecke $\cdot$ Robert Weingart

\title{
The electrical behaviour of rat connexin46 gap junction channels expressed in transfected HeLa cells
}

Received: 7 May 2003 / Accepted: 29 May 2003 / Published online: 12 July 2003

(C) Springer-Verlag 2003

\begin{abstract}
Pairs of human HeLa cells expressing rat connexin 46 were used to study the electrical properties of gap junction channels with the dual voltage-clamp method. The steady-state conductance $\left(g_{\mathrm{j}, \mathrm{ss}}\right)$ had a bellshaped dependence on transjunctional voltage $\left(V_{\mathrm{j}}\right)$. The parameters of the Boltzmann fit were: $V_{\mathrm{j}, 0}=42 \mathrm{mV}$, $g_{\mathrm{j}, \min }=0.12, z=2.5$ (pipette solution: $\mathrm{K}^{+}$aspartate ${ }^{-} ; 2{ }^{\circ} \mathrm{C}$ ). The Boltzmann parameters were sensitive to the ionic composition of the pipette solution $\left(\mathrm{KCl}, \mathrm{K}^{+}\right.$aspartate ${ }^{-}$, $\mathrm{TEA}^{+} \mathrm{Cl}^{-}, \mathrm{TEA}^{+}$aspartate ${ }^{-}$. The $\mathrm{V}_{\mathrm{j}}$-dependent inactivation of the junctional current $I_{\mathrm{j}}$ was approximated by single exponentials (exceptions: two exponentials with $\mathrm{KCl}$ at $V_{\mathrm{j}} \geq 75 \mathrm{mV}$ and $\mathrm{K}^{+}$aspartate ${ }^{-}$at $V_{\mathrm{j}}=125 \mathrm{mV}$ ). The time constant of inactivation $\left(\tau_{\mathrm{i}}\right)$ decreased with increasing $V_{\mathrm{j}}$ and was sensitive to the pipette solution. The larger the ions, the slower the inactivation. Recovery from inactivation followed a single exponential. The time constant of recovery $\left(\tau_{\mathrm{r}}\right)$ increased with increasing $V_{\mathrm{j}}$. Single-channel currents showed a main state, several substates and a residual state. The corresponding conductances $\gamma_{\mathrm{j}, \text { main }}$ and $\gamma_{\mathrm{j}, \text { residual }}$ decreased slightly with increasing $V_{\mathrm{j}}$; extrapolation to $V_{\mathrm{j}}=0 \mathrm{mV}$ yielded values of 152 and $28 \mathrm{pS}$, respectively $\left(\mathrm{K}^{+}\right.$aspartate $\left.{ }^{-} ; 37^{\circ} \mathrm{C}\right)$. The

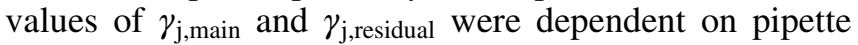

R. Sakai $\cdot$ R. Weingart $(\bullet)$

Department of Physiology, University of Bern,

Bühlplatz 5, 3012 Bern, Switzerland

e-mail: weingart@pyl.unibe.ch

Tel.: +41-31-6318706

Fax: +41-31-6314611

R. Sakai

Brain Science Institute,

The Institute of Physical and Chemical Research (RIKEN),

Wako-shi, 351-0198 Saitama, Japan

C. Elfgang · K. Willecke

Institute of Genetics, University of Bonn,

53117 Bonn, Germany

R. Vogel

Cardiology, Swiss Cardiovascular Centre Bern,

University Hospital, Inselspital, 3008 Bern, Switzerland solution. The ratio $\gamma_{\mathrm{j} \text {,main }} / \gamma_{\mathrm{j} \text {,residual }}$ increased with increasing ionic size, suggesting that the residual state impairs ion permeation more severely than the main state. The $\gamma_{\mathrm{j} \text {,main }}$ data suggest that the ionic selectivity of $\mathrm{Cx} 46$ channels may be controlled primarily by ionic size. Compared with hemichannel results, docking of connexons may modify the channel structure and thereby affect the ionic selectivity of gap junction channels. The open channel probability at steady state $\left(P_{\mathrm{o}}\right)$ decreased with increasing $V_{\mathrm{j}}$. The parameters of the Boltzmann fit were: $V_{\mathrm{j}, 0}=41 \mathrm{mV}, z=2.2\left(\mathrm{~K}^{+}\right.$aspartate $\left.^{-} ; 2{ }^{\circ} \mathrm{C}\right)$.

Keywords Gap junction - Connexin46 - Electrical properties $\cdot$ Conductance $\cdot$ Kinetics $\cdot$ Lens

\section{Introduction}

The lens of the vertebrate eye consists of a core of regularly packed fibre cells and a layer of epithelial cells covering the anterior surface of the organ. A unique feature of this organ is the absence of a vascular system. To maintain tissue homeostasis, the lens relies on metabolic co-operation via gap junctions. Extensive communication via gap junctions exists between the epithelial cells, between the fibre cells and between the two cell types. This has been documented by morphological and functional studies (see [12]). Immunolocalization and molecular biology techniques have identified three gap junction proteins in the lens, the connexins Cx43, Cx46 and Cx50. While epithelial cells express Cx43 [2, 20], fibre cells produce Cx46 and Cx50 [21, 36].

Functional aspects of $\mathrm{Cx} 46$ and $\mathrm{Cx} 50$ gap junctions have already been examined in pairs of Xenopus oocytes injected with rodent mRNA and information obtained on the voltage sensitivity of the gap junction conductance $[11,36,37]$. However, large membrane current noise has prevented the characterization of single channels. To circumvent this problem, attempts have been made to isolate cell pairs from rodent lenses using enzymatic treatments. While this approach has been successful for 
epithelial cells [8], difficulties have been experienced with fibre cells [9]: co-expression of two connexins renders it difficult to determine the electrical properties of identified gap junction channels.

The aim of this study was to explore the electrical properties of $\mathrm{Cx} 46$ gap junction channels in HeLa cells transfected with cDNA coding for rat $\mathrm{Cx} 46$. The experiments were carried out on cell pairs with variable intercellular coupling. Multi-channel and single-channel currents were recorded under different ionic conditions and the conductive and kinetic properties determined. Preliminary data have been published elsewhere in abstract form [22].

\section{Materials and methods}

Cells and culture conditions

Experiments were performed with a clone of human HeLa cells transfected with a cDNA construct containing the coding sequence of rat Cx46. The 1592-bp EcoRI fragment of rat Cx46 cDNA [21] was ligated into the expression vector pBEHpac18 [15] that contained the SV40 early promoter, a polyadenylation signal and a gene conferring resistance to puromycin. In the $\mathrm{Cx} 46$ cDNA fragment all ATG codons upstream of the start codon had been removed. HeLa cells were transfected with $20 \mu \mathrm{g}$ recombinant connexin46-pBEHpac18 plasmid using the calcium phosphate transfection protocol [6]. Between 24 and $48 \mathrm{~h}$ after exposure to DNA, the antibiotic puromycin $(1 \mu \mathrm{g} / \mathrm{ml})$ was added to the medium. Clones were selected after 3 weeks, grown in DMEM (Gibco, Paisley, UK) containing 10\% FCS and $1 \mu \mathrm{g} / \mathrm{ml}$ puromycin (Sigma, St. Louis, MO, USA), passaged weekly and diluted 1:10. For experiments, monolayers of cells $\left(\sim 4 \times 10^{5}\right.$ cells $\left./ \mathrm{cm}^{2}\right)$ were harvested and re-suspended in DMEM containing 10\% FCS $(0.2-$ $1 \times 10^{6}$ cells $\left./ \mathrm{ml}\right)$. Thereafter, the cells were seeded onto sterile glass cover-slips $\left(\sim 10^{4}\right.$ cells $\left./ \mathrm{cm}^{2}\right)$ placed in multi-well culture dishes and used within $24 \mathrm{~h}$ after plating.

\section{Solutions}

Experiments were carried out in modified Krebs-Ringer solution (mM): $\mathrm{NaCl} 150, \mathrm{KCl} 4, \mathrm{CaCl}_{2}, 2, \mathrm{MgCl}_{2} 1$, glucose 5, pyruvate 2, HEPES 5 ( $\mathrm{pH} 7.4$ ). Patch pipettes were filled with normal pipette solution (in mM): $\mathrm{K}^{+}$aspartate ${ }^{-} 120, \mathrm{NaCl} 10, \mathrm{MgCl}_{2} 1, \mathrm{CaCl}_{2} 1$, HEPES 5 (pH 7.2), EGTA 10 (pCa $\cong 8$ ), MgATP 3, through a 0.22$\mu \mathrm{m}$-pore filter. In some experiments, $\mathrm{K}^{+}$aspartate ${ }^{-}$was replaced by equimolar amounts of $\mathrm{KCl}, \mathrm{TEA}^{+} \mathrm{Cl}^{-}$or $\mathrm{TEA}^{+}$aspartate ${ }^{-}$. The specific conductance of the pipette solutions was determined with a conductivity meter (CDM 83; Radiometer, Copenhagen, Denmark) at $27{ }^{\circ} \mathrm{C}$.

\section{Electrical measurements}

Cover-slips with adherent cells were transferred to a chamber superfused at $2 \mathrm{ml} / \mathrm{min}$ with saline at $27{ }^{\circ} \mathrm{C}$. To alter the temperature, saline reservoirs were kept in heated or cooled vessels. The temperature in the chamber was measured with a thermistor positioned close to the cells. The chamber was mounted on the stage of an inverted microscope equipped with phasecontrast optics (Diaphot-TMD, Nikon; Nippon Kogaku, Tokyo, Japan). Patch pipettes were pulled from glass capillaries (GC150F10; Harvard Apparatus, Edenbridge, UK) using a horizontal puller (DMZ-Universal; Zeitz Instruments, Munich, Germany). When filled with solution, they had DC resistances of 3-6 M 2 . Experiments were carried out on cell pairs formed in culture [28]. Each cell of a pair was attached to a pipette. After establishing a G $\Omega$-seal, the membrane patch was disrupted enabling whole-cell recording. The pipettes were connected to separate amplifiers (EPC7; List Electronic, Darmstadt, Germany). A dual voltage-clamp method allowed the membrane potential of each cell to be controlled $\left(V_{1}\right.$, $\left.V_{2}\right)$ and the current flow through each pipette to be measured $\left(I_{1}\right.$, $I_{2}$ ). Initially, the membrane potential of both cells was clamped to $-30 \mathrm{mV}$. Thereafter, a junctional voltage $\left(V_{\mathrm{j}}\right)$ was established by de- or hyperpolarizing cell 1 while maintaining the membrane potential of cell 2 . Under these conditions, $V_{\mathrm{j}}$ corresponds to the voltage between the cells, $V_{\mathrm{j}}=V_{2}-V_{1}$. The current recorded from cell 1 represents the sum of two components, a gap junction current $\left(I_{\mathrm{j}}\right)$ and a non-junctional membrane current $\left(I_{\mathrm{m}, 1}\right)$, the current recorded from cell 2 is thus $-I_{\mathrm{j}}$. Voltage and current signals were stored on FM tape (SE 3000; SE Lab, Feltham, UK). For analysis the signals were filtered at $1 \mathrm{kHz}$ (8-pole Bessel filter) and digitized at $2 \mathrm{kHz}$ (12-bit A/D converter IDA 12120; INDEC Systems, Capitola, Calif., USA). Data acquisition and analysis were performed with the software C-Lab (INDEC Systems). Curve fitting and statistical analysis were done with SigmaPlot and SigmaStat, respectively (Jandel Scientific, Erkrath, Germany). The results are presented as means \pm SEM. The significance of differences between means was established using Student's $t$-test.

\section{Biophysical modelling}

Electrical properties of gap junction channels were modelled by two different approaches. The first method relies on macroscopic data and uses a top-down algorithm by assuming hemichannel properties (VW-model) [33]. The second method uses a bottom-up algorithm such as the Poisson-Nernst-Planck formulation of electrodiffusion, which is based on the combined treatment of selectivity and permeation (PNP-model) [7]. This model has been applied previously to describe the properties of single ion channels [7] as well as single gap junction channels and hemichannels [24]. It considers local chemical interactions depicted by an offset in chemical potential, which probably reflects differences in dehydration, solvation and rehydration energies associated with entry and exit steps of channel permeation. These interactions are modelled by fixed charges distributed along the channel. The purpose of the latter simulation is to demonstrate that specific charge profiles are able to reproduce the essential features of $\mathrm{Cx} 46$ single-channel conductance. However, it would have been beyond the scope of the present work to derive a set of parameters representing the best fit to the problem. $I / V$-curves were calculated using the code solving the PNP equation available at http:// www.pnponline.org./program.php. The PNP solver is accessed via a graphical user interface. The settings of the PNP parameters were as follows: pore length $=100 \AA$, left ion concentration $=120 \mathrm{mM}$, right ion concentration $=120 \mathrm{mM}$, diffusion coefficient of cation $=2.048 \times 10^{-5} \quad \mathrm{~cm}^{2} / \mathrm{s} \quad\left(\mathrm{K}^{+}\right)$, diffusion coefficient of anion $=0.655 \times 10^{-5} \mathrm{~cm}^{2} / \mathrm{s}$ (aspartate $\left.{ }^{-}\right)$, ambient temperature $=27{ }^{\circ} \mathrm{C}$, relative dielectric constant of aqueous pore $=80$. For the comparison with biological data, the $I / V$-curves were transformed into conductance/voltage curves.

\section{Results}

\section{Voltage dependence of gap junction currents}

Voltage pulses of long duration (10 s), variable amplitude $(\leq 150 \mathrm{mV})$ and either polarity were applied to one cell of the pair while the junctional current $I_{\mathrm{j}}$ was recorded from the other. Figure 1A shows records obtained with the pipette solution containing $\mathrm{K}^{+}$aspartate ${ }^{-}$as major charge carriers. Hyperpolarization of cell 2 by $75 \mathrm{mV}\left(V_{2}\right.$, lefthand side) provoked an $I_{\mathrm{j}}$ with time-dependent inactiva- 

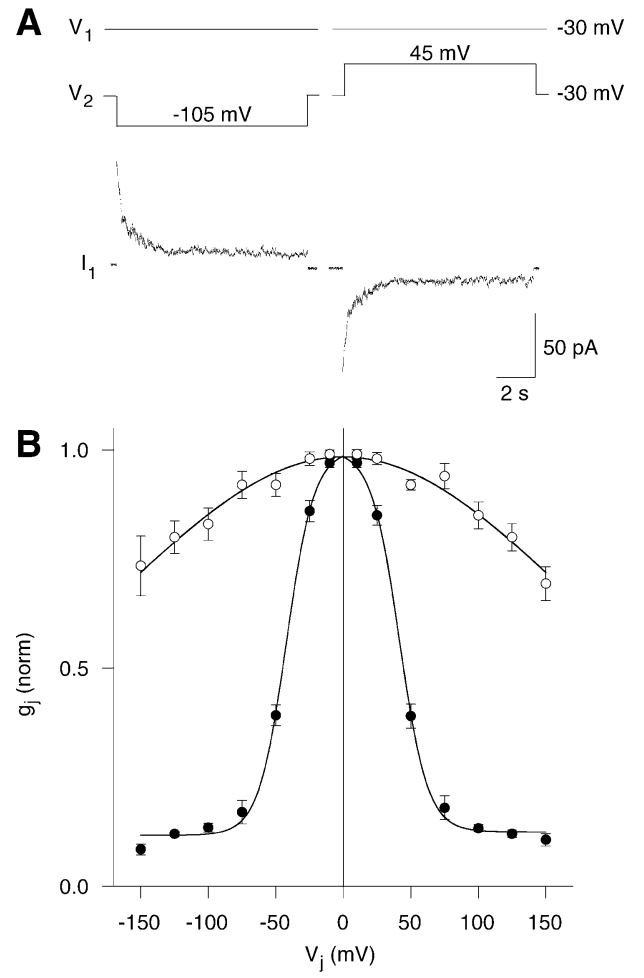

Fig. 1A, B Dependence of the multi-channel currents $I_{j}$ on transjunctional voltage $V_{\mathrm{j}}$ in pairs of HeLa cells expressing rat connexin Cx46 gap junctions. A Responses of $I_{\mathrm{j}}$ to $V_{\mathrm{j}} . V_{1}, V_{2}$ : membrane potential of cell 1 and cell $2 ; I_{1}$ : current measured from cell 1 . Deflections in $V_{2}$ and $I_{1}$ correspond to $V_{\mathrm{j}}$ and $I_{\mathrm{j}}$, respectively. $V_{\mathrm{j}}= \pm 75 \mathrm{mV}$. B Normalized gap junction conductance, $g_{j}$ (norm), determined at the beginning $\left(g_{\mathrm{j}, \text { inst }} ; \bigcirc\right)$ and end $\left(g_{\mathrm{j}, \mathrm{ss}} ; \mathbf{O}\right)$ of $V_{\mathrm{j}}$ pulses, as a function of $V_{\mathrm{j}}$ (ten cell pairs). The curves $g_{\mathrm{j}, \text { inst }}=f\left(V_{\mathrm{j}}\right)$ and $g_{\mathrm{j}, \mathrm{ss}}=f\left(V_{\mathrm{j}}\right)$ show the best fits to Eqs. 1 and 2, respectively. For the Boltzmann parameters, see Table 1

tion ( $I_{1}$, left-hand side). Depolarization of the same magnitude led to a similar $I_{\mathrm{j}}$ of opposite polarity $\left(V_{2}\right.$ and $I_{1}$, right-hand side). To perform a complete experiment, the transjunctional voltage $V_{\mathrm{j}}$ was altered stepwise between \pm 10 and $\pm 150 \mathrm{mV}$. Figure $1 \mathrm{~B}$ summarizes the results from ten cell pairs. The amplitude of $I_{\mathrm{j}}$ was determined at the beginning ( $I_{\mathrm{j}, \text { inst }}$; inst: instantaneous) and end ( $I_{\mathrm{j}, \mathrm{ss}}$; ss: steady state) of each $V_{\mathrm{j}}$ pulse to calculate the conductances $g_{\mathrm{j}, \text { inst }}=I_{\mathrm{j}, \text { inst }} / V_{\mathrm{j}}$ and $g_{\mathrm{j}, \mathrm{ss}}=I_{\mathrm{j}, \mathrm{ss}} / V_{\mathrm{j}}$, respectively. On the one hand, the values of $g_{\text {j,inst }}$ were normalized with respect to the maximal $g_{\mathrm{j} \text {,inst }}$ at small $V_{\mathrm{j}}$ gradients. The normalized values of $g_{\text {j,inst }}$ were plotted as a function of $V_{\mathrm{j}}\left(g_{\mathrm{j}, \text { inst }}=f\left(V_{\mathrm{j}}\right)\right.$, open circles $)$. On the other hand, the values of $g_{\mathrm{j}, \mathrm{ss}}$ were normalized with respect to the $g_{\mathrm{j} \text {,inst }}$ prevailing at each $V_{\mathrm{j}}$. The normalized $g_{\mathrm{j}, \mathrm{ss}}$ were plotted as a function of $V_{\mathrm{j}}\left(g_{\mathrm{j}, \mathrm{ss}}=f\left(V_{\mathrm{j}}\right)\right.$, solid circles $)$. Cell pairs with $g_{\mathrm{j}, \text { inst }}>2 \mathrm{nS}$ were excluded from the analysis to minimize series resistance problems $[3,35]$.

The $g_{\mathrm{j}, \text { inst }}$ data exhibited a slight curvature with a symmetry at $V_{\mathrm{j}}=0 \mathrm{mV}$. The smooth curve represents the best fit of data to:
Table 1 Electrical properties of multi-channel gap junction currents. Means \pm SEM (in parentheses) for negative/positive transjunctional potential $V_{\mathrm{j}}\left(g_{\mathrm{j}, \mathrm{min}}\right.$ is the normalized conductance at large $V_{\mathrm{j}}$

\begin{tabular}{|c|c|c|c|c|}
\hline Pipette solutions & $V_{\mathrm{j}, 0}(\mathrm{mV})$ & $g_{\mathrm{j}, \min }$ & $z$ & $n$ \\
\hline $\mathrm{KCl}$ & $\begin{array}{l}-32.4 / 30.4 \\
(1.1 / 1.6)\end{array}$ & $\begin{array}{l}0.15 / 0.15 \\
(0.01 / 0.02)\end{array}$ & $\begin{array}{l}2.6 / 2.7 \\
(0.2 / 0.3)\end{array}$ & 10 \\
\hline $\mathrm{K}^{+}$aspartate $^{-}$ & $\begin{array}{l}-42.1 / 41.6 \\
(0.5 / 0.7)\end{array}$ & $\begin{array}{l}0.12 / 0.12 \\
0.01 / 0.01\end{array}$ & $\begin{array}{l}2.5 / 2.5 \\
(0.1 / 0.1)\end{array}$ & 10 \\
\hline $\mathrm{TEA}^{+} \mathrm{Cl}^{-}$ & $\begin{array}{l}-45.7 / 44.0 \\
(0.6 / 0.5)\end{array}$ & $\begin{array}{l}0.10 / 0.10 \\
(0.01 / 0.01)\end{array}$ & $\begin{array}{l}2.2 / 2.5 \\
(0.1 / 0.1)\end{array}$ & 9 \\
\hline $\mathrm{TEA}^{+}$aspartate $^{-}$ & $\begin{array}{l}-45.1 / 45.2 \\
(0.5 / 0.6)\end{array}$ & $\begin{array}{l}0.07 / 0.07 \\
(0.01 / 0.01)\end{array}$ & $\begin{array}{l}2.4 / 2.3 \\
(0.1 / 0.1)\end{array}$ & 7 \\
\hline
\end{tabular}

The following differences were not significant statistically (Student's $t$-test): $V_{\mathrm{j}, 0}$ data: $\mathrm{TEA}^{+} \mathrm{Cl}^{-}$vs. TEA ${ }^{+}$aspartate ${ }^{-} ; z$ data: $\mathrm{KCl}$ vs. $\mathrm{K}^{+}$aspartate ${ }^{-}, \mathrm{K}^{+}$aspartate ${ }^{-}$vs. $\mathrm{TEA}^{+} \mathrm{Cl}^{-}, \mathrm{TEA}^{+} \mathrm{Cl}^{-}$vs. $\mathrm{TEA}^{+}$ aspartate

$$
g_{\mathrm{j}, \text { inst }}=\frac{G_{\mathrm{j}}}{e^{\frac{-V_{\mathrm{j}}}{V_{\mathrm{H}}\left(1+e^{\frac{V_{\mathrm{j}}}{V_{\mathrm{H}}}}\right)}}+e^{\frac{V_{\mathrm{j}}}{V_{H}\left(1+e^{-V_{\mathrm{j}}}\right.}}}
$$

(VW-model; Eq. 29 in [33]). $G_{\mathrm{j}}$ is a dimensionless fitting parameter and $V_{\mathrm{H}}$ a decay constant. The analysis yielded the following values: $G_{\mathrm{j}}=2.0 ; V_{\mathrm{H}}=-159 \mathrm{mV}$. At $V_{\mathrm{j}}=0 \mathrm{mV} g_{\mathrm{j} \text {,inst }}$ was 1.0 and 0.85 at $V_{\mathrm{j}}= \pm 100 \mathrm{mV}$.

The $g_{\mathrm{j}, \mathrm{ss}}$ data followed a bell-shaped relationship which was nearly symmetrical. At $V_{\mathrm{j}}=0 \mathrm{mV}, g_{\mathrm{j}, \mathrm{ss}}$ was maximal. Between $V_{\mathrm{j}}= \pm 15$ and $\pm 75 \mathrm{mV}$, it decreased steeply. Beyond $\pm 100 \mathrm{mV}$, it remained virtually constant. The smooth curve represents the best fit of data to the Boltzmann equation applied separately to each voltage polarity:

$g_{\mathrm{j}, \mathrm{ss}}=\frac{1-g_{\mathrm{j}, \min }}{1+e^{\left[A\left(V_{\mathrm{j}}-V_{\mathrm{j}, 0}\right)\right]}}+g_{\mathrm{j}, \min }$

where $g_{\mathrm{j}, \min }$ is the normalized conductance at large $V_{\mathrm{j}}$ and $V_{\mathrm{j}, 0}$ corresponds to the $V_{\mathrm{j}}$ at which $g_{\mathrm{j}, \mathrm{ss}} / g_{\mathrm{j} \text {,inst }}$ is halfmaximally inactivated. $A$ is a constant expressing gating charge, $z q(k T)^{-1}$ [13]. The values obtained from the analysis are given in Table 1 (pipette solution: $\mathrm{K}^{+}$ aspartate ${ }^{-}$).

The voltage dependence of $I_{\mathrm{j}}$ was also examined in the presence of pipette solutions containing $\mathrm{KCl}, \mathrm{TEA}^{+} \mathrm{Cl}^{-}$or TEA $^{+}$aspartate $^{-}$as major charge carriers (signals not shown). The records obtained indicated distinct differences in $V_{\mathrm{j}}$ sensitivity of $I_{\mathrm{j}}$. Figure 2 shows the results of the analysis plotting the normalized $g_{\mathrm{j}, \mathrm{ss}}$ vs. $f\left(V_{\mathrm{j}}\right)$ for the three solutions: $\mathrm{KCl}$ (circles, solid curve); $\mathrm{TEA}^{+}$ $\mathrm{Cl}^{-}$(squares, dashed curve); $\mathrm{TEA}^{+}$aspartate ${ }^{-}$(triangles; dotted curve). The smooth curves represent the best fit of data to the Boltzmann equation. The values obtained from the analysis are given in Table 1. A comparison of the data indicates subtle differences caused by the ions of the pipette solutions. 


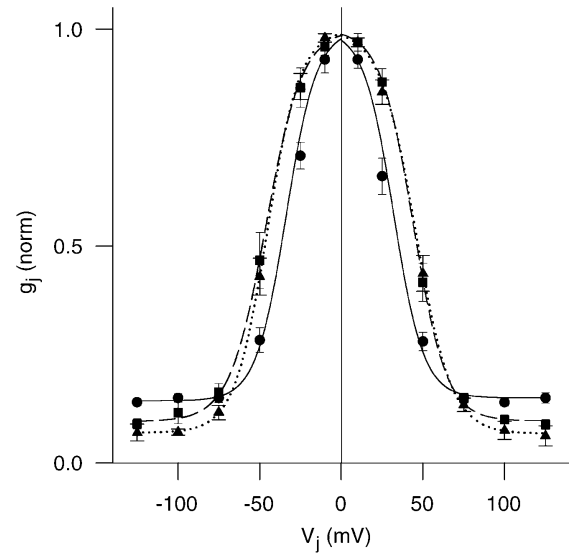

Fig. 2 Effects of intracellular ions on the dependence of $I_{\mathrm{j}}$ on $V_{\mathrm{j}}$. The cells were dialysed with pipette solutions containing $\mathrm{KCl}(\mathbf{O})$, $\mathrm{TEA}^{+} \mathrm{Cl}^{-}(\mathbf{\square})$ or TEA ${ }^{+}$aspartate ${ }^{-}(\boldsymbol{\Delta})$ as major charge carriers. The normalized gap junction conductance at steady state, $g_{\mathrm{j}, \mathrm{ss}}$, is plotted vs. $V_{\mathrm{i}} ; n=10,9$ and 7 cell pairs, respectively. The curves show the best fits to Eq. 2. Solid curve: $\mathrm{KCl}$; dashed curve: $\mathrm{TEA}^{+} \mathrm{Cl}^{-}$; dotted curve: TEA $^{+}$aspartate ${ }^{-}$. For the Boltzmann parameters, see Table 1

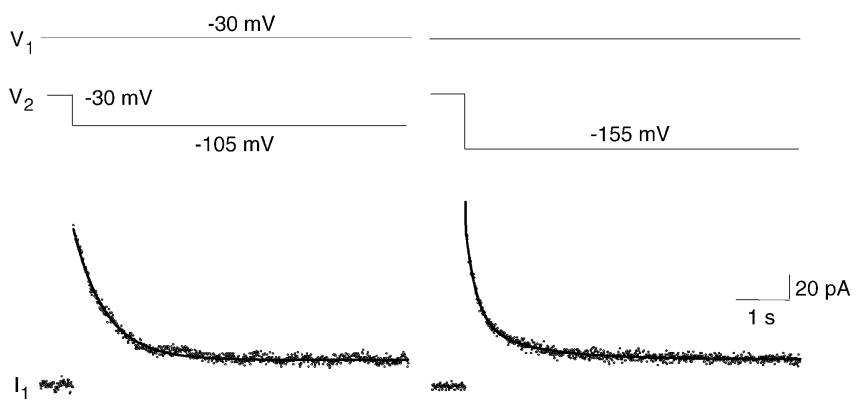

Fig. 3 Influence of $V_{\mathrm{j}}$ on the time course of $I_{\mathrm{j}}$ inactivation. Current traces $I_{1}$ obtained at $V_{\mathrm{j}}=-75 \mathrm{mV}$ (left) and $-125 \mathrm{mV}$ (right). The smooth curves are the best fits of currents to Eqs. 3 and 4

Inactivation of gap junction currents

Next we explored the kinetics of $I_{\mathrm{j}}$ inactivation using pipette solution with $\mathrm{K}^{+}$aspartate ${ }^{-}$. Figure 3 shows signals gained at $V_{\mathrm{j}}=-75 \mathrm{mV}$ (left-hand panel) and $V_{\mathrm{j}}=-125 \mathrm{mV}$ (right-hand panel). The velocity of $I_{\mathrm{j}}$ inactivation was sensitive to the amplitude of $V_{\mathrm{j}}$, with acceleration as $V_{\mathrm{j}}$ increased. To analyse the time course of inactivation, $I_{\mathrm{j}}$ signals were subjected to least-squares curve fitting. At $V_{\mathrm{j}}=-75 \mathrm{mV}$, the best fit was achieved with a single exponential:

$I_{\mathrm{j}}(t)=I_{\mathrm{j} 1} \cdot e^{-\left(\frac{t}{\tau_{\mathrm{i} 1}}\right)}+I_{\mathrm{j}, \mathrm{ss}}$

where $I_{\mathrm{j}}(0)$ corresponds to $I_{\mathrm{j}}$ at time $t=0$ and equals $I_{\mathrm{j} 1}+I_{\mathrm{j}, \mathrm{ss}} ; \tau_{\mathrm{i} 1}$ is the time constant of $I_{\mathrm{j}}$ inactivation. At $V_{\mathrm{j}}=-125 \mathrm{mV}$, the sum of two exponentials provided a better fit:

$I_{\mathrm{j}}(t)=I_{\mathrm{j} 1} \cdot e^{-\left(\frac{t}{\tau_{\mathrm{i} 1}}\right)}+I_{\mathrm{j} 2} \cdot e^{-\left(\frac{t}{\tau_{\mathrm{i} 2}}\right)}+I_{\mathrm{j}, \mathrm{ss}}$
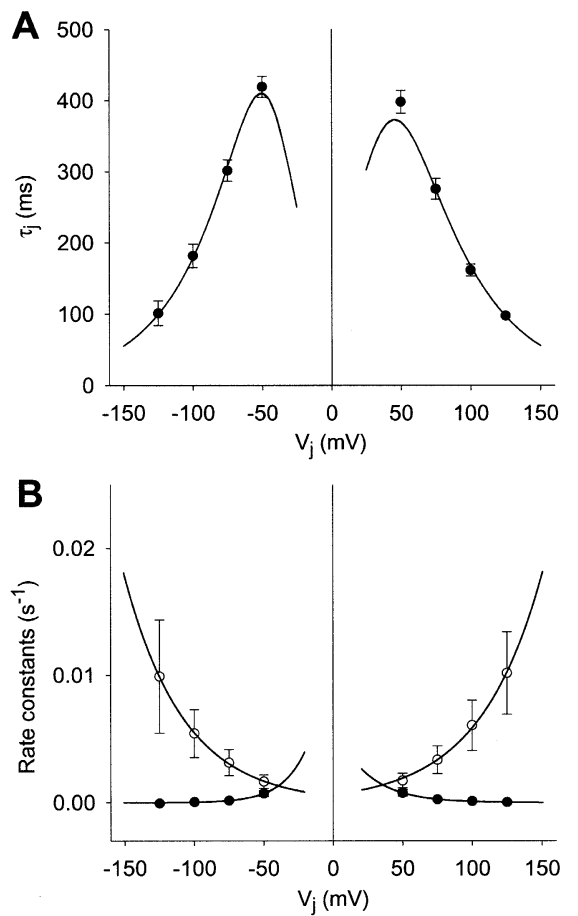

Fig. 4A, B Kinetic properties of $I_{\mathrm{j}}$ inactivation. A Plot of time constants of $I_{\mathrm{j}}$ inactivation, $\tau_{\mathrm{i} 1}$, as functions of $V_{\mathrm{j}}$. Data from ten cell pairs. The curves were calculated from Eq. 9 taking into account the values for $\alpha$ and $\beta$ determined by Eqs. 7 and 8. B The rate constants of channel opening, $\alpha(\mathbf{O})$, and closing, $\beta(\bigcirc)$ as functions of $V_{\mathrm{j}}$. The curves show the best fits to Eqs. 7 and 8. For the kinetic parameters obtained, see Table 2

In this case, $I_{\mathrm{j}}(0)$ equals $I_{\mathrm{j} 1}+I_{\mathrm{j} 2}+I_{\mathrm{j}, \mathrm{ss}}$. The smooth curves indicate the best fit of $I_{\mathrm{j}}$ to Eqs. 3 and 4, respectively. The analysis yielded the following values: $\tau_{\mathrm{i} 1}=240 \mathrm{~ms}$ $\left(V_{\mathrm{j}}=-75 \mathrm{mV}\right) ; \tau_{\mathrm{i} 1}=83 \mathrm{~ms}, \tau_{\mathrm{i} 2}=438 \mathrm{~ms}\left(V_{\mathrm{j}}=-125 \mathrm{mV}\right)$. In the latter case, $\tau_{\mathrm{i} 1}$ and $\tau_{\mathrm{i} 2}$ were different by a factor of 5.3, suggesting that this phenomenon is genuine.

Figure 4A summarizes the inactivation data from ten cell pairs. The values of $\tau_{\mathrm{i}}$ were obtained from individual $I_{\mathrm{j}}$ records, averaged and plotted as a function of $V_{\mathrm{j}}$. For $V_{\mathrm{j}}$ up to $\pm 100 \mathrm{mV}$, the analyses yielded single time constants, $\tau_{\mathrm{i} 1}$, for larger values of $V_{\mathrm{j}}$, fitting with two time constants was more appropriate, $\tau_{\mathrm{i} 1}$ and $\tau_{\mathrm{i} 2}$. The symbols correspond to mean values of $\tau_{\mathrm{i} 1}\left(\tau_{\mathrm{i} 2}\right.$ omitted for clarity). The values at $V_{\mathrm{j}}$ of $25 \mathrm{mV}$ were rejected due to the small $I_{\mathrm{j}}$ amplitude and the poor signal/noise ratio. Over the voltage range analysed, $\tau_{\mathrm{i} 1}$ decreased with increasing $V_{\mathrm{j}}$ for both polarities.

Considering a two-state process (main state $\leftrightarrows$ residual state; see Single-channel conductances), the rate constants for channel opening $(\alpha)$ and closing $(\beta)$ can be estimated according to [13]:

$\alpha=\frac{\frac{g_{\mathrm{j}, \mathrm{ss}}\left(V_{\mathrm{j}}\right)}{g_{\mathrm{j}, \text { inst }}\left(V_{\mathrm{j}}\right)}-g_{\mathrm{j}, \text { min }}}{\left(1-g_{\mathrm{j}, \min }\right) \cdot \tau_{\mathrm{i}}}$

and 

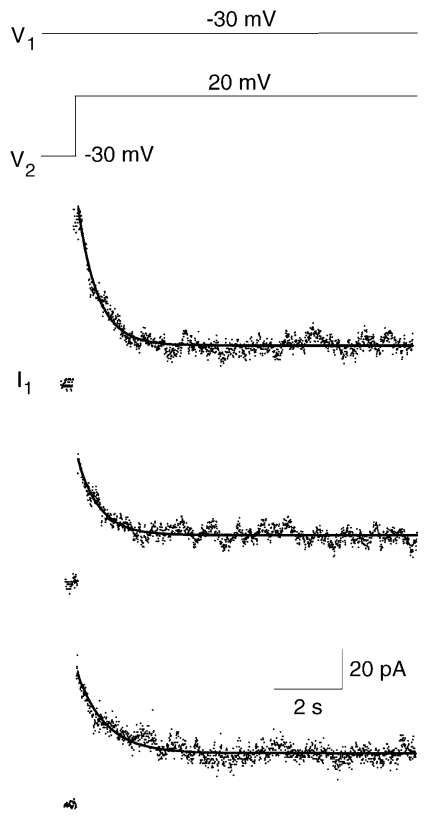

Fig. 5 Influence of pipette solution on the time course of $I_{\mathrm{j}}$ inactivation. $I_{\mathrm{j}}$ records were obtained with pipette solutions containing $\mathrm{KCl}$ (top), $\mathrm{TEA}^{+} \mathrm{Cl}^{-}$(middle) and $\mathrm{TEA}^{+}$aspartate ${ }^{-}$ (bottom). $V_{\mathrm{j}}=50 \mathrm{mV}\left(V_{1}=-80 \mathrm{mV}, V_{2}=-30 \mathrm{mV}\right)$, pulse duration $=10 \mathrm{~s}$. The analyses yielded single time constants. The smooth curves are the best fits of currents to Eq. 3

$\beta=\frac{1-\frac{g_{\mathrm{j}, \mathrm{ss}}\left(V_{\mathrm{j}}\right)}{g_{\mathrm{j}, \text { inst }}\left(V_{\mathrm{j}}\right)}}{\left(1-g_{\mathrm{j}, \min }\right) \cdot \tau_{\mathrm{i}}}$

Using these equations, values for $\alpha$ and $\beta$ were calculated from the data in Fig. 4A and plotted as functions of $V_{\mathrm{j}}$ (Fig. 4B). The graphs $\alpha=f\left(V_{\mathrm{j}}\right)$ (solid circles) and $\beta=f\left(V_{\mathrm{j}}\right)$ (open circles) indicate that $\tau_{\mathrm{i}}$ is governed by $\alpha$ at low $V_{\mathrm{j}}$ and by $\beta$ at large $V_{\mathrm{j}}$. The smooth curves represent the best fit of data to:

$\alpha=\lambda \cdot e^{\left[-A_{\alpha}\left(V_{\mathrm{j}}-V_{\mathrm{j}, 0}\right)\right]}$

and

$\beta=\lambda \cdot e^{\left[A_{\beta}\left(V_{\mathrm{j}}-V_{\mathrm{j}, 0}\right)\right]}$

where $A_{\alpha}$ and $A_{\beta}$ express the voltage sensitivity of the rate constants and $\lambda$ is a constant corresponding to the rate at which $\alpha=\beta$ (prevails at $V_{\mathrm{j}}=V_{\mathrm{j}, 0}$ ) [13]. The analysis yielded similar values for negative/positive $V_{\mathrm{j}}: \lambda=0.0013 /$ $0.0014 \mathrm{~s}^{-1} ; \quad A_{\alpha}=-0.058 / 0.042 \mathrm{mV}^{-1} ; \quad A_{\beta}=-0.024 /$ $0.022 \mathrm{mV}^{-1} ; V_{\mathrm{j}, 0}=-40.2 / 36.5 \mathrm{mV}$. It follows that $\beta>\alpha$ when $V_{\mathrm{j}}>V_{\mathrm{j}, 0}$ and $\beta<\alpha$ when $V_{\mathrm{j}}<V_{\mathrm{j}, 0}$. The combination of Eqs. 7 and 8 enables $\tau_{\mathrm{i} 1}$ to be calculated:

$\tau_{\mathrm{i} 1}=\frac{1}{\alpha+\beta}$

This relationship was used to plot the function $\tau_{\mathrm{i} 1}=f\left(V_{\mathrm{j}}\right)$ for negative and positive $V_{\mathrm{j}}$ (continuous lines in Fig. 4A). The resulting curves show a maximum at $V_{\mathrm{j}} \cong 50 \mathrm{mV}$. There is a reasonable correlation between the curves and
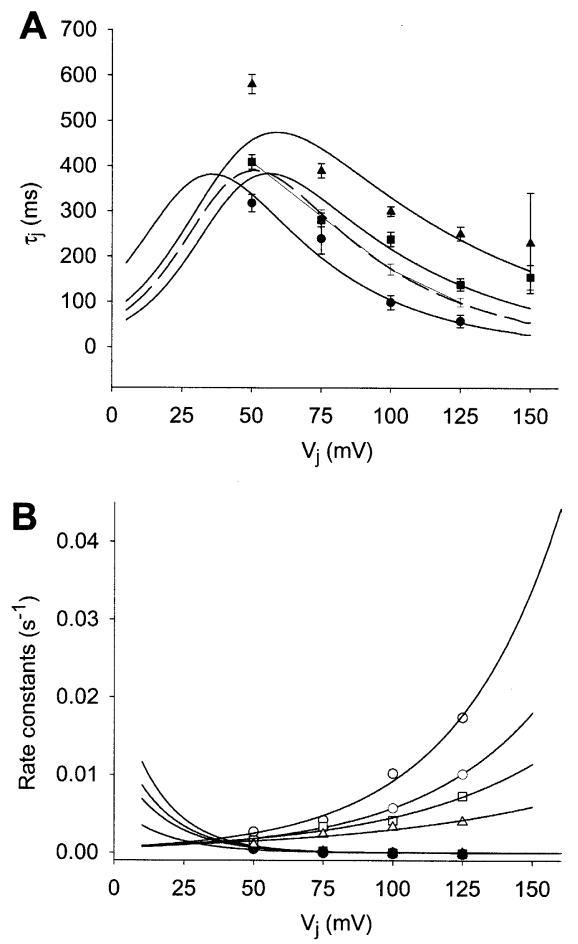

Fig. 6A, B Effects of intracellular ions on kinetic properties of $I_{\mathrm{j}}$ inactivation. A Time constants of $I_{\mathrm{j}}$ inactivation, $\tau_{\mathrm{i}}$, as functions of $V_{\mathrm{j}}$. Values of $\tau_{\mathrm{i} 1}$ obtained at negative and positive $V_{\mathrm{j}}$ were pooled and averaged $\left(-\mathrm{KCl}, n=10 ; \boldsymbol{\mathrm { TEA } ^ { + } \mathrm { Cl } ^ { - } n = 9 ; \boldsymbol { \Delta } \mathrm { TEA } ^ { + } \text { aspartate }}{ }^{-}\right.$ $n=7)$. The smooth curves were calculated from Eq. 9. The dashed curve shows the $\mathrm{K}^{+}$aspartate ${ }^{-}$data from Fig. $4 \mathrm{~A}$ after pooling. $\mathrm{B}$ Rate constants of channel opening, $\alpha$ (solid symbols) and channel closure, $\beta$ (open symbols), deduced from the time constants in $\mathbf{A}$, as functions of $V_{\mathrm{j}}$. The smooth curves show the best fits to Eqs. 7 and 8 . The dashed curve shows the $\mathrm{K}^{+}$aspartate ${ }^{-}$data from Fig. 4B after pooling. For the kinetic parameters obtained, see Table 2

the experimentally determined values of $\tau_{\mathrm{i} 1}$ over the voltage range examined, i.e. $V_{\mathrm{j}}= \pm 50$ to $\pm 125 \mathrm{mV}$.

The kinetics of $I_{\mathrm{j}}$ inactivation were also studied in the presence of other pipette solutions. Figure 5 shows current records obtained with $\mathrm{KCl}$ (top), $\mathrm{TEA}^{+} \mathrm{Cl}^{-}$(middle) and TEA $^{+}$aspartate $^{-}$(bottom). $V_{\mathrm{j}}$ pulses of $50 \mathrm{mV}$ amplitude and $10 \mathrm{~s}$ duration were used $\left(V_{1}=-30 \mathrm{mV}, V_{2}=-80 \mathrm{mV}\right)$. In the case of $\mathrm{KCl}, \mathrm{TEA}^{+} \mathrm{Cl}^{-}$and $\mathrm{TEA}^{+}$aspartate ${ }^{-}$, inactivation followed a single exponential with a $\tau_{\mathrm{i} 1}$ of 333, 417 and $500 \mathrm{~ms}$, respectively (smooth curves). Hence, inactivation of $I_{\mathrm{j}}$ was affected by the ions of the pipette solution. Figure 6 summarizes the data obtained with these solutions (KCl: $n=10$; $\mathrm{TEA}^{+} \mathrm{Cl}^{-}: n=9$; $\mathrm{TEA}^{+}$ aspartate $\left.^{-}: n=7\right)$. The time constants extracted were sampled, averaged and plotted on a logarithmic scale as a function of $V_{\mathrm{j}}$ (Fig. 6A). Negative and positive $V_{\mathrm{j}}$ yielded similar $\tau_{\mathrm{i}}$ values and hence were pooled. In the case of $\mathrm{TEA}^{+} \mathrm{Cl}^{-}$(squares) and $\mathrm{TEA}^{+}$aspartate ${ }^{-}$(triangles), a single time constant was obtained at each $V_{\mathrm{j}}$. In the case of $\mathrm{KCl}$ (circles), a single time constant was found at $V_{\mathrm{j}}=50 \mathrm{mV}$ and two at $V_{\mathrm{j}} \geq 75 \mathrm{mV}$ (for clarity, only $\tau_{\mathrm{i} 1}$ is shown). The different pipette solutions gave rise to 
Table 2 Inactivation parameters of multichannel gap junction currents. Values of $\lambda, V_{\mathrm{j}, 0}, A_{\alpha}$ and $A_{\beta}$ were deduced from the data in Fig. $6 \mathrm{~B}$ ( $\lambda$ constant corresponding to the rate at which $\alpha=\beta$, i.e. at $V_{\mathrm{j}}=V_{\mathrm{j}, 0}, \alpha, \quad \beta$ rate constants of channel opening and closure, respectively, $A_{\alpha}, A_{\beta}$ voltage sensitivity of the respective rate constants)

\begin{tabular}{|c|c|c|c|c|}
\hline Pipette solutions & $\lambda\left(\mathrm{s}^{-1}\right)$ & $V_{\mathrm{j}, 0}(\mathrm{mV})$ & $A_{\alpha}\left(\mathrm{mV}^{-1}\right)$ & $A_{\beta}\left(\mathrm{mV}^{-1}\right)$ \\
\hline $\mathrm{KCl}$ & 0.0014 & 26.5 & 0.056 & 0.026 \\
\hline $\mathrm{K}^{+}$aspartate $^{-}$ & 0.0014 & 39.3 & 0.062 & 0.023 \\
\hline $\mathrm{TEA}^{+} \mathrm{Cl}^{-}$ & 0.0015 & 41.2 & 0.065 & 0.019 \\
\hline TEA $^{+}$aspartate $^{-}$ & 0.0013 & 39.0 & 0.058 & 0.014 \\
\hline
\end{tabular}

distinct relationships between $\tau_{\mathrm{i} 1}$ and $V_{\mathrm{j}}$. In each case, $\tau_{\mathrm{i} 1}$ decreased with increasing $V_{\mathrm{j}}$.

Equations 5 and 6 were then used to calculate the rate constants $\alpha$ and $\beta$ for the different pipette solutions. Figure 6B shows the resulting plots. Solid and open symbols correspond to $\alpha$ and $\beta$, respectively. The solid curves represent the best fit of data to Eqs. 7 and 8. The fitting parameters obtained from the analysis are summarized in Table 2. For comparison, Fig. 6B and Table 2 also include the kinetic data for $\mathrm{K}^{+}$aspartate ${ }^{-}$solution already shown in Fig. 4B (dashed curves, symbols omitted). This involved pooling of the values for positive and negative $V_{\mathrm{j}}$. According to Fig. $6 \mathrm{~B}, \beta=f\left(V_{\mathrm{j}}\right)$ increased with increasing $V_{\mathrm{j}}$ while $\alpha=f\left(V_{\mathrm{j}}\right)$ decreased. The increase in $\beta$ was dependent on the ionic composition of the pipette solution. The smaller the ions, the more pronounced the effect. In contrast, the decrease in $\alpha$ was virtually insensitive to the ions. Hence, the increase in $\tau_{\mathrm{i} 1}$ brought about by the substitution of $\mathrm{KCl}$ for $\mathrm{TEA}^{+}$aspartate ${ }^{-}$can be explained with an increase in $\beta$.

The rate constants gained for $\mathrm{KCl}, \mathrm{TEA}^{+} \mathrm{Cl}^{-}$and $\mathrm{TEA}^{+}$aspartate $^{-}$were then used to calculate $\tau_{\mathrm{i} 1}$ as a function of $V_{\mathrm{j}}$ using Eq. 9. The continuous curves in Fig. 6A illustrate the results. The function $\tau_{\mathrm{i} 1}=f\left(V_{j}\right)$ for $\mathrm{K}^{+}$ aspartate ${ }^{-}$, already shown in Fig. 4A, are also included (dashed curve, symbols omitted). For this purpose, the data for negative and positive $V_{\mathrm{j}}$ were pooled. The graph shows a distinct correlation between $\tau_{\mathrm{i} 1}$ and the ions of the pipette solution for voltages larger than $50 \mathrm{mV}$. The solutions containing the smallest ions, i.e. $\mathrm{KCl}$, gave rise to the smallest $\tau_{\mathrm{i}}$ values, the solution with the largest ions, i.e. $\mathrm{K}^{+}$aspartate ${ }^{-}$, gave rise to the largest $\tau_{\mathrm{i} 1}$ values.

\section{Recovery of $I_{\mathrm{j}}$ from inactivation}

We have also examined the recovery of $I_{\mathrm{j}}$ from inactivation using pipette solution with $\mathrm{K}^{+}$aspartate ${ }^{-}$. The upper panel in Fig. 7A shows the pulse protocol. A conditioning pulse applied to cell 1 (pulse 1) was followed by a test pulse (pulse 2) after a variable delay. Both pulses produced a $V_{\mathrm{j}}$ of $100 \mathrm{mV}$ amplitude and $5 \mathrm{~s}$ duration. They allowed $I_{\mathrm{j}}$ to inactivate maximally and reach a steady state. The lower panel shows superimposed traces indicating that $I_{\mathrm{j}, \text { inst }}$ of pulse 2 grew larger with increasing inter-pulse interval. To examine the role of $V_{\mathrm{j}}$
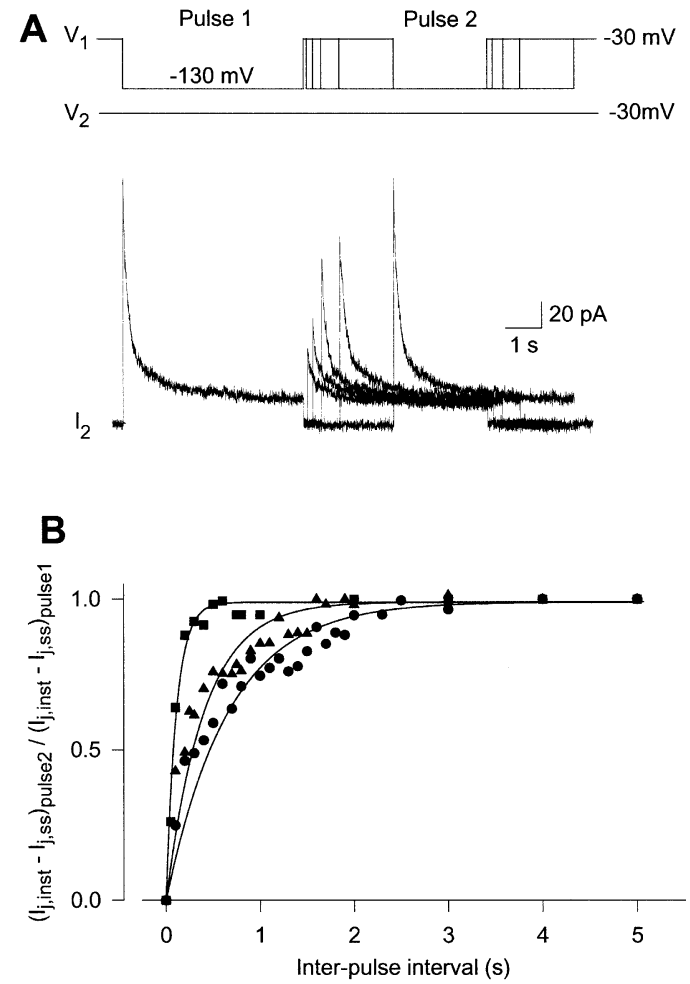

Fig. 7A, B Recovery of $I_{\mathrm{j}}$ from inactivation. A Double pulse protocol used to determine $I_{\mathrm{j}}$ associated with a test pulse (pulse 2) applied at different times after a conditioning pulse (pulse 1). $V_{1}$, $V_{2}$ : superimposed membrane potentials of cells 1 and $2 ; I_{2}$ : family of current traces from cell 2. Deflections in $V_{1}$ and $I_{2}$ correspond to $V_{\mathrm{j}}$ and $I_{\mathrm{j}}$, respectively. B $\left(I_{\mathrm{j}, \text { inst }}-I_{\mathrm{j}, \mathrm{ss}}\right)_{\text {pulse } 2} /\left(I_{\mathrm{j}, \text { inst }}-I_{\mathrm{j}, \mathrm{ss}}\right)_{\text {pulse } 1}$ as a function of inter-pulse interval. Data were obtained at $V_{\mathrm{j}}=50 \mathrm{mV}$ (ם; 5 cell pairs), $75 \mathrm{mV}$ ( $\boldsymbol{\Delta} ; 11$ cell pairs) and $100 \mathrm{mV}(\mathbf{O} ; 8$ cell pairs). The smooth curves are the best fits to Eq. 10

on $I_{\mathrm{j}}$ recovery, we also used pulses of different amplitude (traces not shown). Figure 7B summarizes the results obtained. For each pulse, the current inactivated was calculated, i.e. $I_{\mathrm{j}, \text { inst }}-I_{\mathrm{j}, \mathrm{ss}}$. Thereafter, the values of $I_{\mathrm{j}, \text { inst }}-I_{\mathrm{j}, \mathrm{ss}}$ associated with pulse 2 were normalized relative to $I_{\mathrm{j}, \text { inst }}-I_{\mathrm{j}, \mathrm{ss}}$ associated with pulse 1 and plotted as a function of the inter-pulse interval. The data illustrated were obtained at $V_{\mathrm{j}}=50 \mathrm{mV}$ (squares; $n=5$ ), $75 \mathrm{mV}$ (triangles; $n=11$ ) and $100 \mathrm{mV}$ (circles; $n=8$ ). The smooth curves correspond to the best fit of data to a single exponential:

$\frac{\left(I_{\mathrm{j}, \text { inst }}-I_{\mathrm{j}, \mathrm{ss}}\right)_{\text {pulse2 }}}{\left(I_{\mathrm{j}, \text { inst }}-I_{\mathrm{j}, \mathrm{ss}}\right)_{\text {pulse } 1}}=1-\left(e^{\left(\frac{t}{\tau_{\mathrm{r}}}\right)}\right)$

where $\tau_{\mathrm{r}}$ is the time constant of recovery and $t$ the interpulse interval. The analysis yielded the following values for $\tau_{\mathrm{r}}: V_{\mathrm{j}}=100 \mathrm{mV}: 662 \mathrm{~ms} ; V_{\mathrm{j}}=75 \mathrm{mV}: 404 \mathrm{~ms}$; $V_{\mathrm{j}}=50 \mathrm{mV}: 111 \mathrm{~ms}$. Hence, the larger the inactivation of $I_{\mathrm{j}}$, the slower the recovery. 


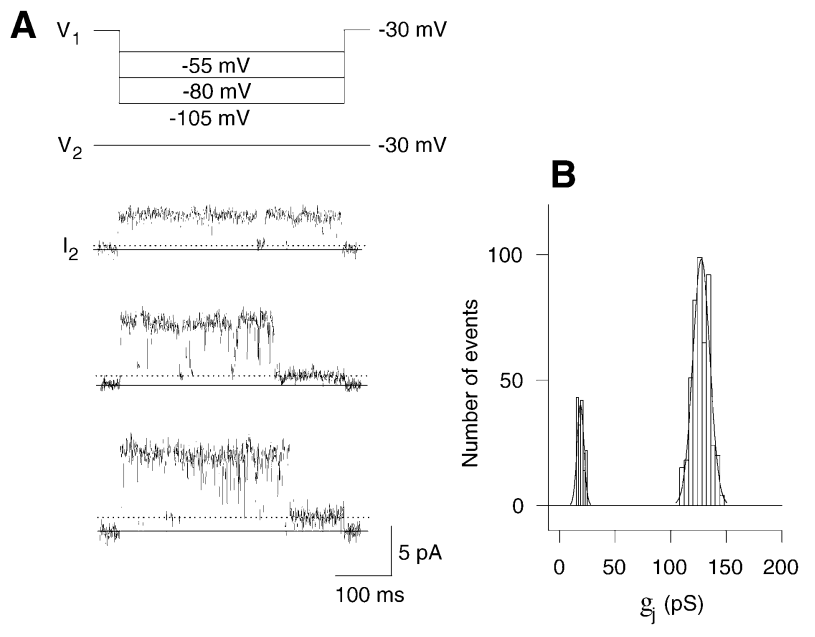

Fig. 8A, B Single-channel currents. A Responses of $I_{\mathrm{j}}$ to $V_{\mathrm{j}}=25,50$ and $75 \mathrm{mV}$ ( $I_{2}$ signals from to top to bottom). $V_{1}, V_{2}$ : membrane potential of cells 1 and $2 ; I_{2}$ : current measured from cell 2 . Deflections in $V_{1}$ and $I_{2}$ correspond to $V_{\mathrm{j}}$ and $I_{\mathrm{j}}$, respectively. Continuous lines indicate zero current, dotted lines the residual current. The analysis yielded the following conductances $\left(\gamma_{\mathrm{j}, \text { main }} /\right.$ $\left.\gamma_{\mathrm{j}, \text { residual }}\right): 136 / 23 \mathrm{pS} ; 130 / 20 \mathrm{pS} ; 118 / 18 \mathrm{pS}$, respectively. B Histogram of single-channel conductances. The analysis included values obtained at $V_{\mathrm{j}}= \pm 50 \mathrm{mV}$ (14 cell pairs). The left and right hand distributions reflect $\gamma_{\mathrm{j}, \text { residual }}$ and $\gamma_{\mathrm{j} \text {,main }}$ data, respectively. The smooth curves show the best fits to Gaussian functions. For the values obtained, see Table 3

\section{Single-channel conductances}

Single-channel events were studied in cell pairs with gap junctions consisting of between one and three operational channels. The protocol involved repetitive application of $V_{\mathrm{j}}$ pulses of 200-500 ms duration, different amplitude $(\leq 100 \mathrm{mV})$ and either polarity. Figure 8A shows signals using pipette solution with $\mathrm{K}^{+}$aspartate ${ }^{-}$. Hyperpolarization of cell $1\left(V_{1}\right)$ led to a $V_{\mathrm{j}}$ of 25,50 and $75 \mathrm{mV}$. The associated $I_{\mathrm{j}}$ signals ( $I_{2}$ traces from top to bottom) showed discrete levels corresponding to the main state, the residual state (dotted lines) and short-lived substates in between. During $V_{\mathrm{j}}$ pulses, $I_{\mathrm{j}}$ did not return to the reference level (solid lines) indicating that the channels failed to close completely. The analysis yielded the following conductances $\left(\gamma_{\mathrm{j}, \text { main }} / \gamma_{\mathrm{j}, \text { residual }}\right): 136 / 23,130 / 20$ and $118 / 18 \mathrm{pS}$, for $V_{\mathrm{j}}$ of 25,50 and $75 \mathrm{mV}$, respectively.

The histograms in Fig. 8B summarize the results from 14 cell pairs plotting the number of events vs. conductance. The values of $\gamma_{\mathrm{j}, \text { residual }}$ and $\gamma_{\mathrm{j} \text {,main }}$ were pooled in 2and 4-pS bins, respectively. To avoid interference from the sensitivity to $V_{\mathrm{j}}$ (see below), this analysis included data at $V_{\mathrm{j}}= \pm 50 \mathrm{mV}$ only. The left- and right-hand distributions correspond to $\gamma_{\mathrm{j}, \text { residual }}$ and $\gamma_{\mathrm{j}, \text { main }}$, respectively. Both data sets showed a binomial distribution approximated by a Gaussian function (smooth curves). The mean values of $\gamma_{\mathrm{j}, \text { main }}$ and $\gamma_{\mathrm{j}, \text { residual }}$ were $127.5 \pm 0.4 \mathrm{pS}$ $(n=471)$ and $19.0 \pm 0.3 \mathrm{pS}(n=175)$, respectively.

To assess the relationships between $V_{\mathrm{j}}$ and $\gamma_{\mathrm{j}}, I_{\mathrm{j}}$ records gained at different $V_{\mathrm{j}}$ were considered. Values of $\gamma_{\mathrm{j} \text {,main }}$
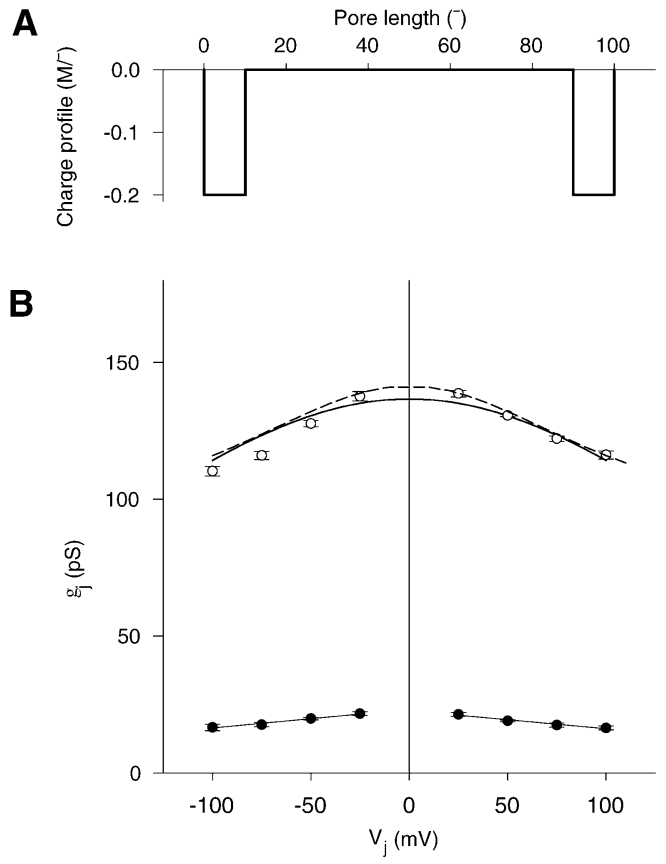

Fig. 9A, B Relationship between single-channel conductances, $\gamma_{\mathrm{j}}$, and $V_{\mathrm{j}}$. Comparison of simulations by the VW- and PNP-models. A Charge density profile of the PNP-model. The graph shows two negative charge regions $(2 \mathrm{~mol} / \mathrm{l})$ located at the pore endings, each occupying $10 \%$ of the pore length. B Conductances $\gamma_{j, \text { main }}(\bigcirc)$ and $\gamma_{\mathrm{j} \text {,residual }}(\mathbf{O})$ as functions of $V_{\mathrm{j}}(14$ cell pairs). Means $\pm \mathrm{SEM}, n=471$ and 175 determinations, respectively. Most error bars are smaller than the symbols. The solid curves correspond to the relationships $\gamma_{\mathrm{j} \text {,main }}=f\left(V_{\mathrm{j}}\right)$ and $\gamma_{\mathrm{j}, \text { residual }}=f\left(V_{\mathrm{j}}\right)$ and show the best fits to the VWmodel. The dashed curve shows the $\gamma_{\mathrm{j}, \text { main }}$ data simulated by the PNP-model, assuming a pore radius of $5.3 \AA$

and $\gamma_{\mathrm{j}, \text { residual }}$ were sampled, averaged and plotted as a function of $V_{\mathrm{j}}$. Figure 9B illustrates the relationships $\gamma_{\mathrm{j}, \text { main }}=f\left(V_{\mathrm{j}}\right)$ (open circles) and $\gamma_{\mathrm{j}, \text { residual }}=f\left(V_{\mathrm{j}}\right)$ (solid circles). $\gamma_{\mathrm{j} \text {,main }}$ showed a slight dependence on $V_{\mathrm{j}}$, i.e. it was maximal at $V_{\mathrm{j}}=0 \mathrm{mV}$ and decreased as $V_{\mathrm{j}}$ was increased. $\gamma_{\mathrm{j}, \text { main }}$ was fitted to the function:

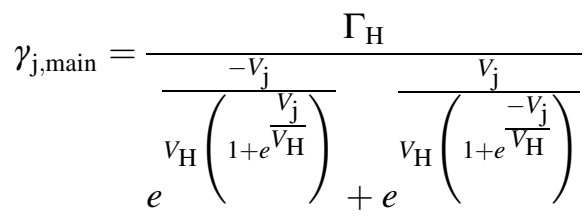

(VW-model; Eq. 29 in [33]). $\Gamma_{\mathrm{H}}$ is the conductance of a hemichannel in the high-conductance state, i.e. the main state, at $V_{\mathrm{j}}=0 \mathrm{mV}$. The analysis yielded the following values: $\Gamma_{\mathrm{H}}=276 \mathrm{pS} ; V_{\mathrm{H}}=-129 \mathrm{mV} . \gamma_{\mathrm{j}, \text { residual }}$ also showed a moderate dependence on $V_{\mathrm{j}}$, i.e. it decreased with increasing $V_{\mathrm{j}}$. Reliable measurements were obtained for $V_{\mathrm{j}}$ between \pm 25 and $\pm 100 \mathrm{mV}$. At $V_{\mathrm{j}}< \pm 25 \mathrm{mV}, \gamma_{\mathrm{j} \text {,residual }}$ events were rare and too small to be resolved (see below). $\gamma_{\mathrm{j}, \text { residual }}$ data were fitted using a standard error minimization procedure. The analysis gave the following values: $\Gamma_{\mathrm{L}}=25 \mathrm{pS}, V_{\mathrm{L}}=-244 \mathrm{mV} . \Gamma_{\mathrm{L}}$ represents the conductance of a hemichannel in the low-conductance, i.e. residual, state, at $V_{\mathrm{j}}=0 \mathrm{mV}$ [33]. 
A
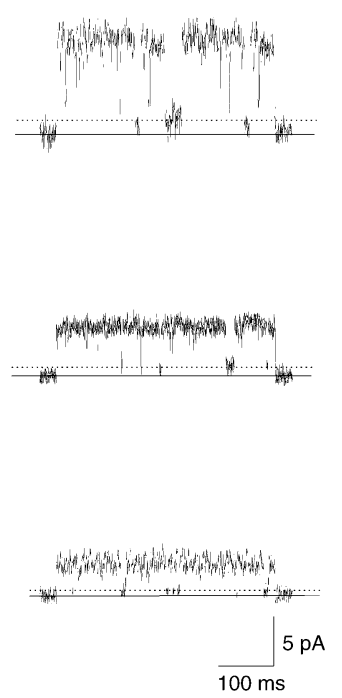
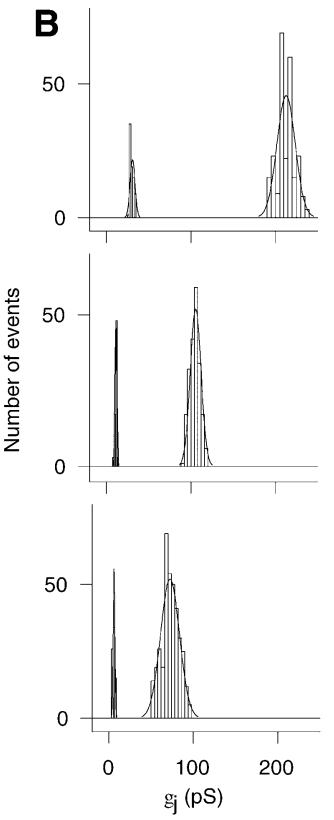

Fig. 10A, B Influence of intracellular ions on single-channel currents. The cells were dialysed with pipette solutions containing $\mathrm{KCl}$ (top), $\mathrm{TEA}^{+} \mathrm{Cl}^{-}$(middle) and $\mathrm{TEA}^{+}$aspartate ${ }^{-}$(bottom) as major charge carriers. A Responses of $I_{\mathrm{j}}$ to a $V_{\mathrm{j}}$ pulse of $50 \mathrm{mV}$ and $400 \mathrm{~ms}\left(V_{1}=-80 \mathrm{mV}, V_{2}=-30 \mathrm{mV}\right)$. Continuous lines indicate zero current, dotted lines residual current. B Histograms of singlechannel conductances. The analysis included values obtained at $V_{\mathrm{j}}= \pm 50 \mathrm{mV}$ only. The left- and right-hand distributions reflect $\gamma_{\mathrm{j}, \text { residual }}$ and $\gamma_{\mathrm{j} \text {,main }}$ data, respectively. The smooth curves show the best fits to Gaussian functions. For the values obtained, see Table 3

Since a gap junction channel consists of two hemichannels in series, $\gamma_{\mathrm{j}, \text { main }}$ and $\gamma_{\mathrm{j}, \text { residual }}$ at $V_{\mathrm{j}}=0 \mathrm{mV}$ can be calculated as $\Gamma_{\mathrm{H}} / 2=138 \mathrm{pS}$ and $\left(\Gamma_{\mathrm{H}}-\Gamma_{\mathrm{L}}\right) /$ $\left(\Gamma_{\mathrm{H}}+\Gamma_{\mathrm{L}}\right)=23 \mathrm{pS}$, respectively. Taking into account the values of $Q_{10}$ (see Influence of temperature on gap junction currents), $\gamma_{\mathrm{j}, \text { main }}$ and $\gamma_{\mathrm{j} \text {,residual }}$ at $37{ }^{\circ} \mathrm{C}$ would be 152 and $28 \mathrm{pS}$, respectively.

To explore the ionic permeability of $\mathrm{Cx} 46$ channels, unitary currents were also recorded with pipette solutions containing $\mathrm{KCl}, \mathrm{TEA}^{+} \mathrm{Cl}^{-}$or $\mathrm{TEA}^{+}$aspartate ${ }^{-}$. In the presence of $\mathrm{TEA}^{+}$aspartate ${ }^{-}, I_{\mathrm{j}}$ records often showed critical signal/noise ratios. In these cases, the currents were analysed using an all-point procedure. Figure 10A shows selected $I_{\mathrm{j}}$ traces elicited by a standard $V_{\mathrm{j}}$ pulse $(50 \mathrm{mV}, 400 \mathrm{~ms})$. Each trace exhibited two prominent levels attributable to the main and residual states (dotted lines). In the presence of $\mathrm{KCl}, \gamma_{\mathrm{j}, \text { main }}$ and $\gamma_{\mathrm{j} \text {,residual were }}$ 207 and $33 \mathrm{pS}$, respectively (top). With $\mathrm{TEA}^{+} \mathrm{Cl}^{-}$, the respective conductances were 108 and $13 \mathrm{pS}$ (middle), with $\mathrm{TEA}^{+}$aspartate ${ }^{-}, 65$ and $6 \mathrm{pS}$ (bottom). Hence, $\gamma_{\mathrm{j}, \text { main }}$ and $\gamma_{\mathrm{j} \text {,residual }}$ decreased with increasing ionic size of the major charge carriers. Figure 10B summarizes the data. Values of $\gamma_{\mathrm{j} \text {,residual }}$ and $\gamma_{\mathrm{j} \text {,main }}$ were sampled in 2- and 4-pS bins, respectively, and plotted as frequency histograms. The two distributions correspond to the $\gamma_{\mathrm{j}, \text { residual }}$ and $\gamma_{\mathrm{j}, \text { main }}$ data. The smooth curves represent the best fit of data to a Gaussian function. Table 3 summarizes the results of the

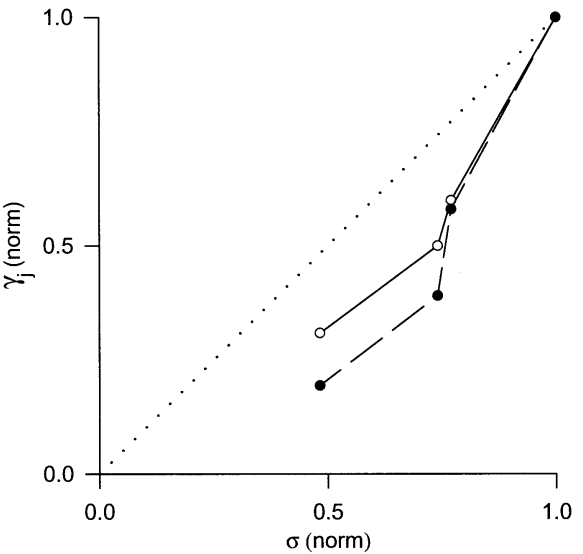

Fig. 11 Selective permeability of single channels. Plot of the normalized channel conductances $\gamma_{\mathrm{j}, \text { main }}(\bigcirc)$ and $\gamma_{\mathrm{j}, \text { residual }}(\mathbf{O}) \mathrm{vs}$. normalized conductance of the pipette solution, $\sigma$. Pipette solution containing $\mathrm{KCl}$ was used as reference. The dotted line indicates identical ionic mobility in the channel pore and in bulk solution

Table 3 Single-channel conductances $\left(\gamma_{\mathrm{j}}\right)$ for the main and residual conductance states. Means \pm SEM. Values in parentheses give the number of cell pairs and the number of observations. Channel conductances were obtained at $V_{\mathrm{j}}=50 \mathrm{mV}$ ( $\sigma$ conductance of pipette solution)

\begin{tabular}{|c|c|c|c|}
\hline Pipette solutions & $\gamma_{\mathrm{j}, \text { main }}(\mathrm{pS})$ & $\gamma_{\mathrm{j}, \text { residual }}(\mathrm{pS})$ & $\sigma(\mathrm{mS} / \mathrm{cm})$ \\
\hline $\mathrm{KCl}$ & $\begin{array}{l}212.7 \pm 0.9 \\
(8 / 248)\end{array}$ & $\begin{array}{l}31.5 \pm 0.4 \\
(8 / 71)\end{array}$ & 17.5 \\
\hline $\mathrm{K}^{+}$aspartate $^{-}$ & $\begin{array}{l}127.5 \pm 0.4 \\
(14 / 471)\end{array}$ & $\begin{array}{l}19.0 \pm 0.2 \\
(14 / 175)\end{array}$ & 13.5 \\
\hline $\mathrm{TEA}^{+} \mathrm{Cl}^{-}$ & $\begin{array}{l}108.8 \pm 0.4 \\
(5 / 209)\end{array}$ & $\begin{array}{l}12.3 \pm 0.1 \\
(5 / 71)\end{array}$ & 13.0 \\
\hline $\mathrm{TEA}^{+}$aspartate $^{-}$ & $\begin{array}{c}65.7 \pm 0.6 \\
(10 / 307)\end{array}$ & $\begin{array}{c}6.1 \pm 0.4 \\
(10 / 75)\end{array}$ & 8.4 \\
\hline
\end{tabular}

analysis and includes the values for $\mathrm{K}^{+}$aspartate ${ }^{-}$(see Fig. 8B).

Figure 11 shows a normalized plot of the channel conductance, $\gamma_{\mathrm{j}}$, as a function of the conductance of the pipette solution, $\sigma$. The values of $\gamma_{\mathrm{j}}$ were taken from the experiments described above, the values of $\sigma$ were measured with a conductivity meter (see Table 3 ). The $\mathrm{KCl}$ pipette solution served as reference. The symbols correspond to $\gamma_{\mathrm{j}, \text { main }}$ (open circles) and $\gamma_{\mathrm{j}, \text { residual }}$ data (solid circles). The dotted line represents the function $\sigma=m \cdot \gamma_{j}$ with $m=1$, assuming identical ionic mobility in the channel pore and in bulk solution. Neither $\gamma_{\mathrm{j} \text {,main }}$ nor $\gamma_{\mathrm{j}, \text { residual }}$ fulfilled this prediction, suggesting interactions between the ions and the channel structure.

\section{Simulations with the PNP-model}

For calculations with the PNP-model, the gap junction channel is divided into ten segments of piecewise constant and fixed charges. Segments 1 and 10 include the intracellular endings of the channel, while segments 5 
and 6 represent the docking area of the hemichannels. Independent of charge polarity, $\gamma_{j, \text { main }}$ increased with increasing $\left|V_{\mathrm{j}}\right|$ when charges were fixed near the docking zone, i.e. in segments 4-6 (data not shown). However, the opposite behaviour can be simulated by placing fixed charges of either polarity close to the proximity of the cytosolic channel ending, i.e. in segments 1, 2, 9 and 10.

As determined experimentally, $\gamma_{\mathrm{j}, \text { main }}$ of a $\mathrm{Cx} 46$ channel decreases from about 135 to $110 \mathrm{pS}$ when $V_{\mathrm{j}}$ is increased from 25 to $100 \mathrm{mV}$ (see Fig. 9B). This behaviour can be approximated by the PNP-model when fixed negative charges are placed in segments 1 and 10 . Positive charges that produced conductances of the same order are very small and thus the channel conductance becomes almost independent of $V_{\mathrm{j}}$. The graph in Fig. 9A shows the charge density profile comprising two negatively charged regions $(2 \mathrm{~mol} / \mathrm{l})$, each occupying $10 \%$ of the pore length and located towards the intracellular end. Figure 9B includes the result of the respective simulation. Choosing a pore radius of $5.3 \AA$ (dashed curve) resulted in a satisfactory agreement between the experimental data and the PNP-model.

\section{Open channel probability}

At steady state the channels flickered primarily between the main state and residual state. Hence, single-channel records allowed the determination of the probability of a channel's being in the main state, $P_{\mathrm{o}}$. The pulse protocol involved the application of a $V_{\mathrm{j}}$ of long duration (20-30 s) and different amplitude. The initial segment of each $I_{\mathrm{j}}$ record was discarded to avoid interference from timedependent inactivation and substates [28]. Figure 12A shows records gained with the $\mathrm{K}^{+}$aspartate ${ }^{-}$pipette solution. The currents were elicited by a $V_{\mathrm{j}}$ of $25 \mathrm{mV}$ (top), $50 \mathrm{mV}$ (middle) and $100 \mathrm{mV}$ (bottom). They indicate that the dwell time at discrete levels is correlated with the amplitude of $V_{\mathrm{j}}$. At $25 \mathrm{mV}$, the channel flickered rarely and was preferentially in the main state. At $50 \mathrm{mV}$, it flickered more frequently and spent less time in the main state and more time in the residual state. At $100 \mathrm{mV}$, it flickered rarely and was mainly in the residual state.

The records in Fig. 12A and others were used to assess $P_{\mathrm{o}}$. The time in the main state was determined and divided by the record duration. The values of $P_{\mathrm{o}}$ were averaged and plotted vs. $V_{\mathrm{j}}$ (Fig. 12B). $P_{\mathrm{o}}$ decreased sigmoidally from 1 to 0 as $V_{\mathrm{j}}$ increased from 0 to $100 \mathrm{mV}$. The continuous curve represents the best fit of data to the Boltzmann equation using the following values: $V_{\mathrm{j}, 0}=40.6 \pm 1.9 \mathrm{mV} ; z=2.2 \pm 0.3$ (ten cell pairs; see Voltage dependence of gap junction currents). This $V_{\mathrm{j}, 0}$ is close to that obtained from the function $g_{\mathrm{j}, \mathrm{ss}}=f\left(V_{\mathrm{j}}\right)$, i.e. $41.4 \mathrm{mV}$ (see Table 1).

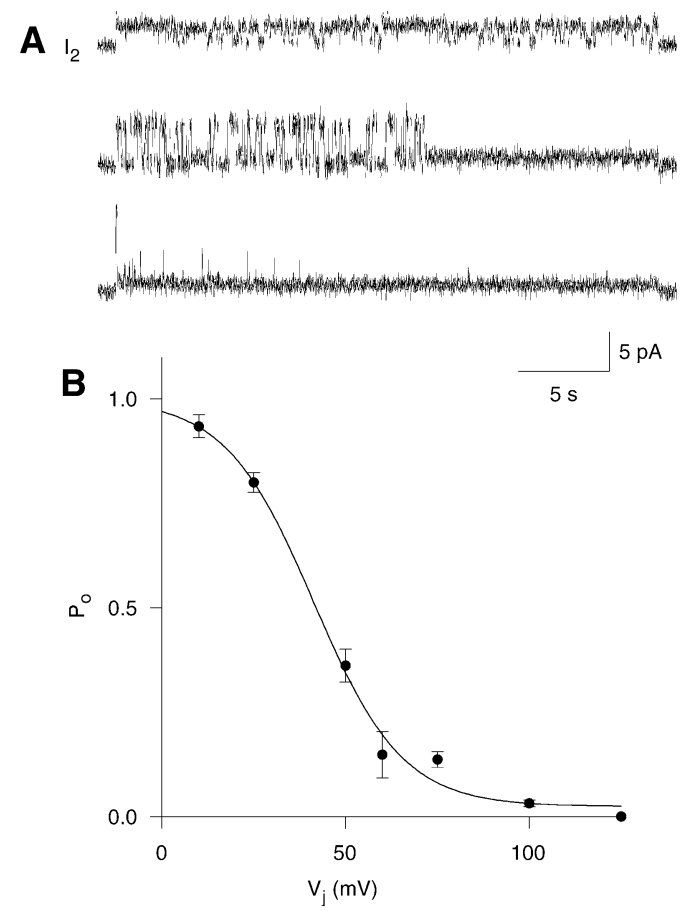

Fig. 12A, B Effects of $V_{\mathrm{j}}$ on probability of the channel open state, $P_{\mathrm{o}}$. A Segments of $I_{\mathrm{j}}$ records from cell pairs with a single operational gap junction channel obtained at steady-state. Currents traces gained at $V_{\mathrm{j}}=25 \mathrm{mV}$ (top), $50 \mathrm{mV}$ (middle) and $100 \mathrm{mV}$ (bottom). B Relationship between $P_{\mathrm{o}}$ and $V_{\mathrm{j}}$. Values of $P_{\mathrm{o}}$ were determined from long-lasting records (20-30 s) during steady-state conditions. The continuous curve shows the best fit to the Boltzmann equation

Influence of temperature on gap junction currents

To obtain further insight into the biophysical properties of Cx46 channels, the effect of temperature on $I_{\mathrm{j}}$ was examined with pipette solution containing $\mathrm{K}^{+}$aspartate ${ }^{-}$. Figure 13A shows segments of continuous records gained at different temperatures. To determine $I_{\mathrm{j}, \text { inst }}$ and $I_{\mathrm{j}, \mathrm{ss}}, V_{\mathrm{j}}$ pulses of $50 \mathrm{mV}$ amplitude and $10 \mathrm{~s}$ duration were delivered to cell 1 and the currents displayed at expanded time scale. To monitor the transitions between temperatures, $V_{\mathrm{j}}$ pulses of $25 \mathrm{mV}$ amplitude and $200 \mathrm{~ms}$ duration were applied and the signals presented on a compressed time scale.

At $17{ }^{\circ} \mathrm{C}$ (left-hand side), $I_{\mathrm{j}}$ inactivated slightly with time $\left(g_{\mathrm{j}, \text { inst }}=1.23 \mathrm{nS}, g_{\mathrm{j}, \mathrm{ss}}=0.75 \mathrm{nS}, \tau_{\mathrm{i} 1}=1,100 \mathrm{~ms}\right)$. At $37^{\circ} \mathrm{C}$ (middle), it inactivated substantially due to disproportionate increases of $I_{\mathrm{j}, \mathrm{inst}}$ and $I_{\mathrm{j}, \mathrm{ss}} \quad\left(g_{\mathrm{j}, \mathrm{inst}}=1.77 \mathrm{nS}\right.$, $g_{\mathrm{j}, \mathrm{ss}}=0.48 \mathrm{nS}, \tau_{\mathrm{i} 1}=256 \mathrm{~ms}$ ). Return to $17{ }^{\circ} \mathrm{C}$ (right hand side) led to a recovery $\left(g_{\mathrm{j}, \mathrm{inst}}=1.21 \mathrm{nS}, g_{\mathrm{j}, \mathrm{ss}}=0.69 \mathrm{nS}\right.$, $\left.\tau_{\mathrm{i} 1}=714 \mathrm{~ms}\right)$. In five cell pairs, $V_{\mathrm{j}}$ was altered systematically to obtain a family of $I_{\mathrm{j}}$ records at 17 and $37{ }^{\circ} \mathrm{C}$. Figure 13B summarizes the results. The ratios $g_{\mathrm{j}, \mathrm{ss}} / g_{\mathrm{j}, \text { inst }}$ were averaged and plotted as functions of $V_{\mathrm{j}}$. For clarity, only half of each data set is shown (positive $V_{\mathrm{j}}: 17{ }^{\circ} \mathrm{C}$ data; negative $V_{\mathrm{j}}: 37{ }^{\circ} \mathrm{C}$ data). The smooth curves represent the best fit of data to the Boltzmann equation 
A
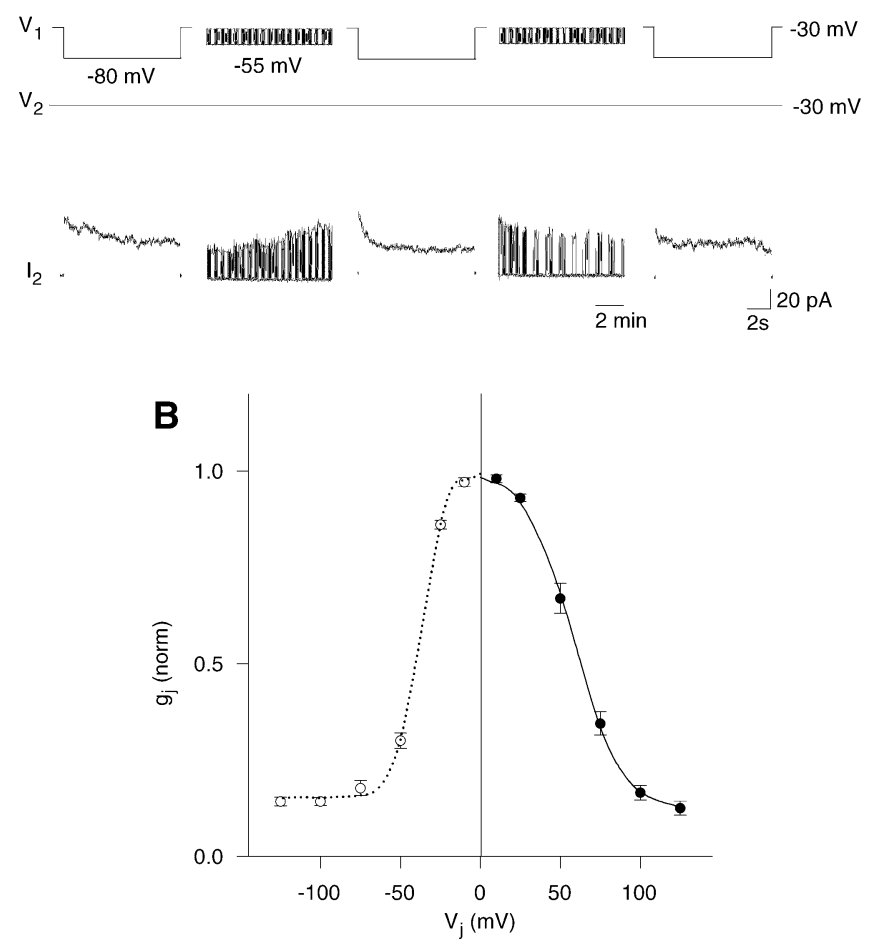

Fig. 13A, B Influence of temperature on multi-channel currents. A Segments of continuous records gained at $17{ }^{\circ} \mathrm{C}$ (left), $37{ }^{\circ} \mathrm{C}$ (middle) and $17{ }^{\circ} \mathrm{C}$ (right). To determine $I_{\mathrm{j}, \text { inst }}$ and $I_{\mathrm{j}, \mathrm{ss}}$, long $V_{\mathrm{j}}$ pulses $(10 \mathrm{~s}, 50 \mathrm{mV})$ were administered to cell 1 . To monitor transitions between temperatures, short $V_{\mathrm{j}}$ pulses $(200 \mathrm{~ms}, 25 \mathrm{mV})$ were applied. Note the different time scale. B Plot of normalized conductance at steady state, $g_{\mathrm{j}, \mathrm{ss}}$, vs. $V_{\mathrm{j}}$. Data were obtained at $17^{\circ} \mathrm{C}$ (O) and $37{ }^{\circ} \mathrm{C}(\bigcirc)$. For clarity, only half of each data set is shown (five cell pairs each). The smooth curves show the best fits to Eq. 2. For the Boltzmann parameters, see text

A
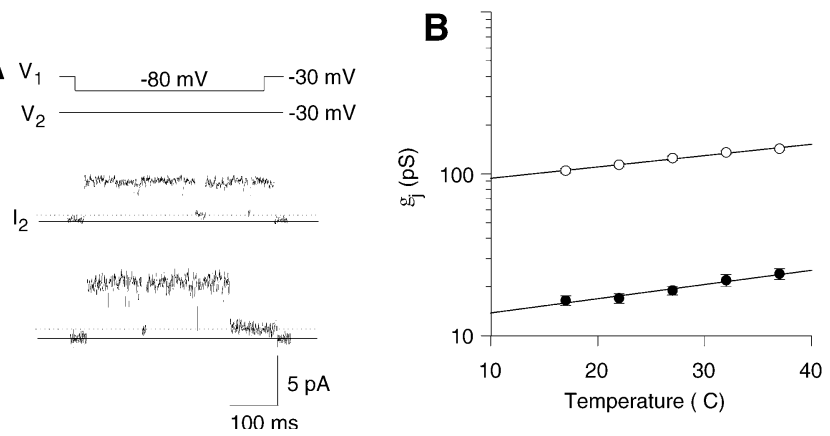

Fig. 14A, B Influence of temperature on single-channel currents. A Responses of $I_{\mathrm{j}}$ to a $V_{\mathrm{j}}$ pulse of $50 \mathrm{mV}$ and $300 \mathrm{~ms}\left(V_{1}=-80 \mathrm{mV}\right.$, $V_{2}=-30 \mathrm{mV}$ ) obtained at $17{ }^{\circ} \mathrm{C}$ (upper trace) and $37^{\circ} \mathrm{C}$ (lower trace). The continuous lines indicate zero current, the dotted lines residual current. B Channel conductances $\gamma_{\mathrm{j} \text {,main }}(\bigcirc)$ and $\gamma_{\mathrm{j} \text {,residual }}$ () on a logarithmic scale as functions of temperature. The sloping lines show the best fits to Eq. 12 using the temperature coefficients, $Q_{10}$, of 1.1 and 1.2 , respectively for following values: $17{ }^{\circ} \mathrm{C}: V_{\mathrm{j}, 0}=58.5 \mathrm{mV}, g_{\mathrm{j}, \min }=0.12$, $z=1.7 ; 37^{\circ} \mathrm{C}: V_{\mathrm{j}, 0}=38 \mathrm{mV}, g_{\mathrm{j}, \min }=0.15, z=3.3$.

These parameters and those obtained at $27{ }^{\circ} \mathrm{C}$ using the same pipette solution, i.e. $\mathrm{K}^{+}$aspartate ${ }^{-}$(see Table 1), were used to assess the temperature coefficient, $\mathrm{Q}_{10}$, of the Boltzmann parameters. Averages of $V_{\mathrm{j}, 0}, g_{\mathrm{j}, \min }$ and $z$ were plotted on a logarithmic scale vs. temperature (not shown). Over the range examined, i.e. $17-37{ }^{\circ} \mathrm{C}$, each parameter increased with increasing temperature. The data were analysed using:

$F_{T}=F_{17} \cdot Q_{10}^{\left[\frac{T-17}{10}\right]}$

where $T$ is the temperature in ${ }^{\circ} \mathrm{C}, F$ the parameter under investigation, and $F_{17}$ the value of the parameter at the reference temperature, i.e. $17{ }^{\circ} \mathrm{C}$. The best fit of data was obtained for the following $Q_{10}$ values: $1.25,1.2$ and 1.38 for $V_{\mathrm{j}, 0}, g_{\mathrm{j}, \min }$ and $z$, respectively.

Figure 14A shows unitary currents recorded at different temperature. An increase from 17 to $37{ }^{\circ} \mathrm{C}$ (upper and lower $I_{2}$ trace) led to an increase in conductance, i.e. $\gamma_{\mathrm{j} \text {,main }}$ increased from 104 to $143 \mathrm{pS}$ and $\gamma_{\mathrm{j} \text {,residual }}$ from 17 to $24 \mathrm{pS}$. This corresponds to a 1.38-fold and 1.41-fold increase, respectively. Figure 14B summarizes the results from 22 cell pairs including the data shown in Fig. 8B. Individual values of $\gamma_{\mathrm{j} \text {,main }}(n=1,739)$ and $\gamma_{\mathrm{j}, \text { residual }}(n=352)$ were averaged and plotted on a logarithmic scale vs. temperature. Over the range examined, i.e. $17-37{ }^{\circ} \mathrm{C}$, $\gamma_{\mathrm{j}, \text { main }}$ (open circles) and $\gamma_{\mathrm{j}, \text { residual }}$ (solid circles) increased with increasing temperature. The solid lines represent the best fit of data to Eq. 12 using a $Q_{10}$ of 1.1 and 1.2 for $\gamma_{\mathrm{j}, \text { main }}$ and $\gamma_{\mathrm{j}, \text { residual }}$, respectively.

\section{Discussion}

Our data indicate that rat $\mathrm{Cx} 46$ channels resemble other vertebrate gap junction channels, e.g. Cx30 [28], Cx40 [4] or Cx43 [27]. They exhibit several conductance states and are sensitive to $V_{\mathrm{j}}$. We show that many of the basic electrical properties are dependent on the ionic composition of the pipette solution. Control solution containing $\mathrm{K}^{+}$aspartate ${ }^{-}$was used to mimic physiological conditions. During the interventions, these ions were replaced by $\mathrm{TEA}^{+}$and/or $\mathrm{Cl}^{-}$.

\section{Voltage gating of $I_{\mathrm{j}}$}

The $g_{\mathrm{j}}$ of Cx 46 gap junctions is gated by $V_{\mathrm{j}}$, but not by $V_{\mathrm{m}}$ (latter data not shown). With regard to $V_{\mathrm{j}}$ gating, the analysis furnished the relationships $g_{\mathrm{j}, \text { inst }}=f\left(V_{\mathrm{j}}\right)$ and $g_{\mathrm{j}, \mathrm{ss}}=f\left(V_{\mathrm{j}}\right)$, which characterize the instantaneous and steady-state properties, respectively (see Fig. 1B). On the one hand, $g_{\mathrm{j}, \text { inst }}$ decreased slightly with increasing $V_{\mathrm{j}}$, leading to a moderate curvature of $g_{\mathrm{j}, \text { inst }}=f\left(V_{\mathrm{j}}\right)$. A comparison of Figs. $1 \mathrm{~B}$ and 9 (pipette solution: $\mathrm{K}^{+}$ aspartate $\left.^{-}\right)$indicates that the relationships $g_{\mathrm{j}, \text { inst }}=f\left(V_{\mathrm{j}}\right)$ and $\gamma_{\mathrm{j}, \text { main }}=f\left(V_{\mathrm{j}}\right)$ resemble each other, suggesting that the 
former reflects a genuine property of single channels. The $g_{\mathrm{j} \text {,inst }}$ data were approximated considering an exponential relationship between the hemichannel conductance and $V_{\mathrm{j}}$ $[23,26,33]$. On the other hand, $g_{j, s s}$ decreased sharply with increasing $V_{\mathrm{j}}$ producing a symmetrical, bell-shaped function $g_{\mathrm{j}, \mathrm{ss}}=\mathrm{f}\left(V_{\mathrm{j}}\right)$ best described by two Boltzmann equations.

With pipette solution containing $\mathrm{K}^{+}$aspartate ${ }^{-}$, the analysis of $g_{\mathrm{j}, \mathrm{ss}}$ data yielded the following Boltzmann parameters: $V_{\mathrm{j}, 0}=-42 / 42 \mathrm{mV}, g_{\mathrm{j}, \min }=0.12 / 0.12$ and $z=2.5 /$ 2.5 (negative/positive $V_{\mathrm{j}}$; see Table 1). Replacing $\mathrm{K}^{+}$and aspartate ${ }^{-}$in the pipette solution by TEA ${ }^{+}$and/or $\mathrm{Cl}^{-}$ showed that intracellular ions affect $g_{\mathrm{j}, \mathrm{min}}$ and $V_{\mathrm{j}, 0}$, but not $z$ (see Table 1). Substitution of the major charge carriers led to the sequence $\mathrm{KCl}>\mathrm{K}^{+}$aspartate ${ }^{-}>\mathrm{TEA}^{+} \mathrm{Cl}^{-}>\mathrm{TEA}^{+}$ aspartate $^{-}$for $g_{\mathrm{j}, \min }$. Moreover, there was a close match between $g_{\mathrm{j}, \min }$ and $\gamma_{\mathrm{j} \text {,residual }} / \gamma_{\mathrm{j}, \text { main }}$ for solutions with $\mathrm{KCl}$ (0.15 and 0.15$), \mathrm{K}^{+}$aspartate ${ }^{-}(0.13$ and 0.15$), \mathrm{TEA}^{+} \mathrm{Cl}^{-}$ (0.10 and 0.11$)$ or $\mathrm{TEA}^{+}$aspartate ${ }^{-}(0.07$ and 0.09$)$, i.e. $g_{\mathrm{j}, \text { min }}$ and $\gamma_{\mathrm{j}, \text { residual }} / \gamma_{\mathrm{j}, \text { main }}$ follow the same ion sequence. Hence, the changes in $g_{\mathrm{j}, \mathrm{min}}$ are accounted for by alterations in $\gamma_{\mathrm{j}, \text { main }}$ and $\gamma_{\mathrm{j}, \text { residual }}$. Exchange of the pipette solution yielded the sequence $\mathrm{KCl}<\mathrm{K}^{+}$aspartate $^{-}<\mathrm{TEA}^{+}$ $\mathrm{Cl}^{-} \cong \mathrm{TEA}^{+}$aspartate ${ }^{-}$for $V_{\mathrm{j}, 0}$. Substitution of $\mathrm{KCl}$ for $\mathrm{TEA}^{+}$aspartate ${ }^{-}$provoked an increase in $V_{\mathrm{j}, 0}$ by $13-$ $14 \mathrm{mV}$. Conceivably, this reflects a change in $\mathrm{P}_{\mathrm{o}}$. Examining Cx43 channels, we found similar effects on $V_{\mathrm{j}, 0}$ and $g_{\mathrm{j}, \min }$ caused by the pipette solutions [27].

The Boltzmann parameters obtained under quasiphysiological ionic conditions, i.e. pipette solution with $\mathrm{K}^{+}$aspartate ${ }^{-}$, are similar to those reported for mouse lens fibre cells $\left(V_{\mathrm{j}, 0}=38.6 \mathrm{mV}, g_{\mathrm{j}, \mathrm{min}}=0.11, z=2.2\right)$ [9]. This may be fortuitous since fibre cells express both $\mathrm{Cx} 46$ and Cx50. Our data agree with those for rat $\mathrm{Cx} 46$ channels expressed in $\mathrm{N} 2 \mathrm{~A}$ cells $\left(V_{\mathrm{j}, 0}=48 \mathrm{mV}, g_{\mathrm{j}, \min }=0.11, z=2\right)$ [14], but deviate from those for mouse Cx46 expressed in Xenopus oocytes $\left(V_{\mathrm{j}, 0}=67 \mathrm{mV}, g_{\mathrm{j}, \mathrm{min}}=0.1, z=2.2\right.$ [37]; $\left.V_{\mathrm{j}, 0}=66 \mathrm{mV}, g_{\mathrm{j}, \min }=0.23, z=2[11]\right)$. The latter may reflect the lower temperature used, i.e. $20-22{ }^{\circ} \mathrm{C}$. Our data obtained at $17{ }^{\circ} \mathrm{C}$ partially support this view $\left(V_{\mathrm{j}, 0}=58.5 \mathrm{mV}, g_{\mathrm{j}, \min }=0.12, z=1.7\right)$.

\section{Kinetics of $I_{\mathrm{j}}$ inactivation}

The inactivation of $\mathrm{Cx} 46$ channels is controlled by voltage. The larger $V_{\mathrm{j}}$, the faster the inactivation of $I_{\mathrm{j}}$. Hence, $\mathrm{Cx} 46$ channels behave like other $\mathrm{Cx}$ channels (e.g. $[4,27,28])$. In the presence of $\mathrm{K}^{+}$aspartate ${ }^{-}, I_{\mathrm{j}}$ decreased as a single exponential for $V_{\mathrm{j}} \leq 100 \mathrm{mV}\left(\tau_{\mathrm{i} 1}\right)$ and as a sum of two exponentials for $V_{\mathrm{j}}>100 \mathrm{mV}\left(\tau_{\mathrm{i} 1}\right.$ and $\tau_{\mathrm{i} 2}$; see Fig. 3). Substitution of the pipette solution indicated that the kinetics of $I_{\mathrm{j}}$ inactivation are also affected by intracellular ions (see Figs. 5 and 6). In the presence of $\mathrm{KCl}$, a second time constant was already evident at $V_{\mathrm{j}}>75 \mathrm{mV}$. With $\mathrm{TEA}^{+} \mathrm{Cl}^{-}$and $\mathrm{TEA}^{+}$aspartate ${ }^{-}, \tau_{\mathrm{i} 2}$ was not detectable up to $V_{\mathrm{j}} \leq 125 \mathrm{mV}$. Hence, the dissociation of $\tau_{\mathrm{i}}$ into two components is emphasized by large $V_{\mathrm{j}}$ and small ions, i.e. $I_{\mathrm{j}}$ inactivates with a single time constant at quasi-physiological conditions $\left(\mathrm{K}^{+}\right.$aspartate ${ }^{-}$and small to moderate $\left.V_{\mathrm{j}}\right)$. The functions $\alpha=\mathrm{f}\left(V_{\mathrm{j}}\right)$ and $\beta=\mathrm{f}\left(V_{\mathrm{j}}\right)$ derived from $\tau_{\mathrm{i} 1}$ data indicated that $\alpha$ is less voltage sensitive than $\beta$ (see Figs. 4B and 6B and Table 2), i.e. $\alpha>\beta$ when $V_{\mathrm{j}}<V_{\mathrm{j}, 0}$ and $\alpha<<\beta$ when $V_{\mathrm{j}}>V_{\mathrm{j}, 0 .}$. Hence, at high $V_{\mathrm{j}}$ the conductance state of the channels is primarily determined by the closing rate constant.

Gap junction channels preferentially exhibit two conductance states, i.e. $\gamma_{\mathrm{j}, \text { main }}$ and $\gamma_{\mathrm{j}, \text { residual }}$. Since each channel consists of two hemichannels, hc1 and hc2, the 2 conductive states can be ascribed to three conformational states, hc $1_{\text {high }}$-hc $2_{\text {high }}$ and hc $1_{\text {high }}-\mathrm{hc} 2_{\text {low }}$ or hc $1_{\text {low }}-\mathrm{hc} 2_{\text {high }}$ [33]. Assuming first-order reactions between conformational states, the state machine predicts single time constants for $I_{\mathrm{j}}$ inactivation. Hence, this scheme seems to conflict with the observation of a second time constant. Whilst it is conceivable that, $\tau_{\mathrm{i} 2}$ may be an artefact caused by series resistance problems, this seems unlikely because cell pairs with $g_{\mathrm{j}, \text { inst }}>2 \mathrm{nS}$ were discarded from the analysis. Alternatively, two time constants may exist, the slower one not always being resolvable. Adverse conditions for its detection include small currents and/or slow inactivation, situations prevailing at small $V_{\mathrm{j}}$ and/or in the presence of large ions. As far as the significance of $\tau_{\mathrm{i} 2}$ is concerned, several possibilities come to mind: (i) a second residual state, (ii) subconductance states, (iii) a closed state and (iv) electrostatic interaction between ions and the channel wall. With respect to (i), a fourth conformational state, $\mathrm{hc} 1_{\text {low }}$-hc $2_{\text {low }}$, may lead to a third conductive state (between $\gamma_{\mathrm{j} \text {,residual }}$ and zero) and hence an extra time constant. However, simulation studies have shown that the probability of such a state is extremely low [33] and hence its effect may be negligible. With regard to (ii), substates have been observed preferentially early during $V_{\mathrm{j}}$ pulses (see also [28]). This would be consistent with the finding that dynamic (i.e. $\alpha$ and $\beta$ ) and steadystate data (i.e. $g_{\mathrm{j}, \mathrm{ss}} / g_{\mathrm{j}, \text { inst }}$ ) reveal a different $V_{\mathrm{j}, 0}$ (compare Tables 1 and 2). With respect to (iii), it has been reported that the incidence of channel closed states increases with increasing $V_{\mathrm{j}}$ [1]. Hence, this possibility cannot be ruled out. With regard to (iv), charge separation during current flow may occur due to interactions between the ions and the channel wall. This would be consistent with the finding that small ions favour the presence of a second time constant.

Replacing the pipette solution showed that the relationship $\tau_{\mathrm{i} 1}=\mathrm{f}\left(V_{\mathrm{j}}\right)$ was also affected by the intracellular ions (see Fig. 6A). Replacing $\mathrm{Cl}^{-}$by aspartate ${ }^{-}$increased $\tau_{\mathrm{i} 1}$, irrespective of the cation. Likewise, replacing $\mathrm{K}^{+}$with $\mathrm{TEA}^{+}$also increased in $\tau_{\mathrm{i} 1}$, irrespective of the anion. In other words, for $\tau_{\mathrm{i} 1}$ to reach a given value, $V_{\mathrm{j}}$ had to be increased when changing from $\mathrm{KCl}$ to $\mathrm{K}^{+}$aspartate ${ }^{-}$, $\mathrm{TEA}^{+} \mathrm{Cl}^{-}$and $\mathrm{TEA}^{+}$aspartate ${ }^{-}$solution. This shift along the $V_{\mathrm{j}}$ axis suggests that more energy is required for $I_{\mathrm{j}}$ inactivation in the presence of larger ions. This would be consistent with screening of surface charges of connexins and thereby altering of the electric field across the channels. These arguments are valid for voltages larger than $50 \mathrm{mV}$. At smaller voltages, there is considerable 
disagreement between experimental and calculated values of $\tau_{\mathrm{i} 1}$. This reflects the fact that $\tau_{\mathrm{i} 1}$ data were not only scarce but also inaccurate, especially in the case of large ions and small currents. The data also indicate that the increase of $\tau_{\mathrm{i} 1}$ in the presence of larger ions is caused by a decrease in $\beta$ (see Fig. 6B). This was most prominent at larger $V_{\mathrm{j}}$. There was virtually no change in $\alpha$. Examining Cx43 channels and running computer simulations, we have made similar observations [29]. Conceivably, electrical interactions between ions and channel surface charges may affect the inactivation kinetics of $I_{\mathrm{j}}$.

Published data on the kinetics of $I_{\mathrm{j}}$ inactivation are contradictory. Some investigators have reported a single time constant (amphibian blastomeres [13]; hamster Cx43 [34]; rat Cx32 [5]; human Cx45 [19]; mouse Cx30 [28]), others two (rat $\mathrm{Cx} 40$ [16]; zebrafish retina [18]). In rat $\mathrm{Cx} 43$, we have also found two time constants at $V_{\mathrm{j}}>100 \mathrm{mV}$ [29]. However, in this case $\tau_{\mathrm{i} 2}$ was more prominent in the presence of large ions ${\left(\mathrm{TEA}^{+} \text {aspartate }\right.}^{-}$ vs. $\mathrm{KCl}$ ). This may reflect differences in surface charge among connexin channels.

\section{Kinetics of $I_{\mathrm{j}}$ restitution}

The recovery of $I_{\mathrm{j}}$ from inactivation was studied in the presence of $\mathrm{K}^{+}$aspartate ${ }^{-}$solution. Its time course followed a single exponential resulting in the time constant $\tau_{\mathrm{r}}$ (see Fig. 7). The behaviour of $\tau_{\mathrm{r}}=f\left(V_{\mathrm{j}}\right)$ and $\tau_{\mathrm{i}}=f\left(V_{\mathrm{j}}\right)$ was complementary. A small $V_{\mathrm{j}}$ gave rise to slow inactivation followed by fast recovery, and vice versa (compare Figs. 4 and 7). This behaviour offers an additional means of controlling the extent of functional coupling between adjacent cells, especially in the case of repetitive changes in $V_{\mathrm{j}}$. This mechanism may be relevant in cardiac tissue, e.g. in the sinoatrial node since it expresses Cx46 and is prone to rhythmic changes [31].

Reports in the literature dealing with $I_{\mathrm{j}}$ recovery are scarce. An early study reported single exponentials with time constants identical to those of $I_{\mathrm{j}}$ inactivation (amphibian blastomeres [13]). Subsequent exploratory studies have yielded single exponentials with $\tau_{\mathrm{r}}>\tau_{\mathrm{i}}$ (hamster heart [34]; chicken heart [30]; bass retina [17]) and $\tau_{\mathrm{r}}$ alone (rat Cx46 expressed in Xenopus oocytes [11]).

\section{Single-channel properties}

Cx46 channels exhibit several conductance states: a main state, several substates, a residual state and a closed state. The main and residual states were long lived while substates, interposed between the two, were short lived and hence difficult to study (see Fig. 8A). Closed states were seen in the presence of chemical uncouplers (e.g. heptanol; data not shown). Current transitions between channel open states were fast $(<2 \mathrm{~ms})$, those involving the closed state were slow $(5-15 \mathrm{~ms})$. The residual state explains the incomplete decline of $g_{\mathrm{j}}$ at large $V_{\mathrm{j}}$ (see
Figs. 1B and 2). These results are consistent with the current concept of gap junction channel operation $[4,27$, 28]. Values of $\gamma_{\mathrm{j} \text {,main }}$ and $\gamma_{\mathrm{j} \text {,residual }}$ were determined under different conditions. Under quasi-physiological conditions $\left(\mathrm{K}^{+}\right.$aspartate ${ }^{-}$solution; $T=37{ }^{\circ} \mathrm{C}$; extrapolated to $\left.V_{\mathrm{j}, 0}=0 \mathrm{mV}\right)$, the predicted values are 152 and $28 \mathrm{pS}$, respectively. These values are comparable to those for rat Cx46 expressed in N2A cells (140 and $27 \mathrm{pS}$; pipette solution: $\mathrm{CsCl}$ ) [14]. However, they deviate from those of lens fibre cells [9]. That study reported a $\gamma_{j}$ histogram with three peaks $\left(78,136\right.$ and $207 \mathrm{pS}$; pipette solution: $\mathrm{K}^{+}$ aspartate $^{-} ; T=22{ }^{\circ} \mathrm{C}$ ), attributing the larger values to channels characteristic of fibre cells.

Detailed analysis revealed that $\gamma_{\mathrm{j} \text {,main }}$ and $\gamma_{\mathrm{j} \text {,residual }}$ are both sensitive to $V_{\mathrm{j}}$, i.e. both decreased with increasing $V_{\mathrm{j}}$ (see Fig. 9). This is consistent with $g_{\text {j,inst }}=f\left(V_{\mathrm{j}}\right)$ (see Fig. 1B). The $\gamma_{\mathrm{j}}$ data were fitted with an equation for homotypic channels assuming rectifying hemichannels [33]. This prediction has been verified in transfected HeLa cells [25, 26] and injected oocytes [23].

Our experiments also showed that the channel conductances depend on the ions in the pipette solution. Substituting solutions, we found that the sequence for $\gamma_{\mathrm{j}, \text { main }}$ and $\gamma_{\mathrm{j}, \text { residual }}$ are identical and match that for the conductivity of the pipette solution, $\sigma: \mathrm{KCl}>\mathrm{K}^{+}$aspartate $^{-}>\mathrm{TEA}^{+} \mathrm{Cl}^{-}>\mathrm{TEA}^{+}$aspartate ${ }^{-}$(see Table 3). Moreover, $\gamma_{\mathrm{j}, \text { residual }}$ was more susceptible to changes in $\sigma$ than $\gamma_{\mathrm{j} \text {,main }}$ (see Fig. 11). This is also evident from the following observations: (i) the ratio $\gamma_{\mathrm{j}, \text { residual }} / \gamma_{\mathrm{j} \text {,main }}$ did not remain constant, i.e. it was $0.15,0.15,0.11$ and 0.09 for the respective solutions; (ii) the ratio $\gamma_{\mathrm{j}}\left(\mathrm{TEA}^{+}\right.$ aspartate $\left.^{-}\right) / \gamma_{\mathrm{j}}(\mathrm{KCl})$ for the main state and residual state was 0.31 and 0.19 , respectively. Hence, the residual state is a more prominent hindrance for ion transfer than the main state as previously reported for $\mathrm{Cx} 43$ channels [27]. Furthermore, the conductance data in Table 3 can be used to estimate relative selectivity ratios. A comparison of the $\gamma_{\mathrm{j} \text {,main }}$ and $\gamma_{\mathrm{j} \text {,residual }}$ data obtained with pipette solutions of identical anions leads to a mean ratio for $\mathrm{K}^{+}: \mathrm{TEA}^{+}$of 1:0.51 and 1:0.36, respectively [procedure: average of $\gamma_{\mathrm{j}, \text { main }}\left(\mathrm{TEA}^{+} \mathrm{Cl}^{-}\right) / \gamma_{\mathrm{j}, \text { main }}(\mathrm{KCl})$ and $\gamma_{\mathrm{j}, \text { main }}\left(\mathrm{TEA}^{+}\right.$aspartate $\left.^{-}\right) / \gamma_{\mathrm{j}, \text { main }}\left(\mathrm{K}^{+}\right.$aspartate $\left.^{-}\right)$, respectively average of $\gamma_{\mathrm{j}, \text { residual }}\left(\mathrm{TEA}^{+} \mathrm{Cl}^{-}\right) / \gamma_{\mathrm{j} \text {,residual }}(\mathrm{KCl})$ and $\gamma_{\mathrm{j}, \text { residual }}\left(\mathrm{TEA}^{+}\right.$aspartate $\left.^{-}\right) / \gamma_{\mathrm{j}, \text { residual }}\left(\mathrm{K}^{+}\right.$aspartate $\left.\left.^{-}\right)\right]$. Conversely, a comparison of $\gamma_{\mathrm{j}, \text { main }}$ and $\gamma_{\mathrm{j}, \text { residual }}$ data gained with solutions of identical cations leads to a mean ratio for $\mathrm{Cl}^{-}$:aspartate of 1:0.6 and 1:0.55, respectively. This implies that $\mathrm{K}^{+}$ passes more readily than $\mathrm{TEA}^{+}$through a channel in the main state and residual state, and $\mathrm{Cl}^{-}$more easily than aspartate ${ }^{-}$. Moreover, the residual state impairs TEA $^{+}$ more effectively than aspartate ${ }^{-}$. This is consistent with the view that $\mathrm{Cx} 46$ channels discriminate cations and anions on the basis of ionic rather than hydrated radii.

Our $\gamma_{\mathrm{j}}$ data alone do not allow absolute ionic selectivities to be deduced. Matrix calculations yield four equations of which only three are linearly independent. This is because the sum of cations and anions is invariant in each pipette solution. This problem can be approached considering the selectivity data of $\mathrm{Cx} 46$ hemichannels. 
These channels reportedly prefer cations to anions $\left(\mathrm{K}^{+}: \mathrm{Cl}^{-}=10: 1\right)$ and obey the selectivity sequence $\mathrm{Cs}^{+}>\mathrm{K}^{+}>\mathrm{Na}^{+}>\mathrm{Li}^{+}>\mathrm{TMA}^{+}>\mathrm{TEA}^{+}$(1.19:1.0:0.8:0.64:0.34: $0.2)[23,32]$. Using our $\gamma_{j \text {,main }}$ data and an equation specifying this $\mathrm{K}^{+}: \mathrm{Cl}^{-}$ratio, the calculated conductance contributed by aspartate ${ }^{-}$was negative, thus violating physico-chemical principles. Using our $\gamma_{\mathrm{j}, \text { main }}$ data and the ratio $\mathrm{K}^{+}: \mathrm{TEA}^{+}=1: 0.2$, we obtained the selectivity sequence $\mathrm{K}^{+}>\mathrm{Cl}^{-}>$aspartate ${ }^{-}>\mathrm{TEA}^{+}$(1.0:0.95:0.33:0.2). This suggests that $\mathrm{Cx} 46$ gap junction channels, unlike their hemichannels, exhibit no general preference for cations to anions. Instead, their ionic selectivity appears to be controlled by ionic size. Hence, docking of hemichannels may introduce structural modifications involved in setting the ionic selectivity of gap junction channels. However, this conclusion conflicts with a report claiming that the ionic selectivity of $\mathrm{Cx} 46$ hemichannels is maintained in Cx46 gap junction channels [24].

The open probability of $\mathrm{Cx} 46$ channels decreased with increasing $V_{\mathrm{j}}$ obeying a sigmoidal function $P_{\mathrm{o}}=f\left(V_{\mathrm{j}}\right)$ (see Fig. 12B). The analysis provided the following Boltzmann parameters (pipette solution: $\mathrm{K}^{+}$aspartate ${ }^{-}$): $V_{\mathrm{j}, 0}=41 \mathrm{mV}, z=2$. Hence, $g_{\mathrm{j}, \min }$ cannot be explained by a partial decrease in $P_{\mathrm{o}}$ (see Voltage gating of $I_{\mathrm{j}}$ ). These values are consistent with those obtained from the relationship $g_{\mathrm{j}, \mathrm{ss}}=f\left(V_{\mathrm{j}}\right)$ (see Table 1). For comparison, mouse $\mathrm{Cx} 40$ expressed in HeLa cells yield a similar $V_{\mathrm{j}, 0}$ value for $P_{\mathrm{o}}=f\left(V_{\mathrm{j}}\right)$ and $g_{\mathrm{j}, \mathrm{ss}}=f\left(V_{\mathrm{j}}\right)$ data [4]. The same finding has been reported for rat $\mathrm{Cx} 32$ in Schwann cells [5]. However, in HeLa cells expressing mouse $\mathrm{Cx} 30, V_{\mathrm{j}, 0}$ gained from $P_{\mathrm{o}}$ data is significantly larger than that from $g_{\mathrm{j}, \mathrm{ss}}$ data [28]. This has been explained by interactions among channels, an effect which may be connexin specific.

\section{PNP-model simulations}

The PNP-model was originally developed to describe ion channels in isolated cells [7]. Recently, it has also been applied to gap junction channels and hemichannels [24]. With our own $\gamma_{j \text {,main }}$ data gained with $\mathrm{K}^{+}$aspartate ${ }^{-}$ solution, it was possible to model the conductance and the rectification of a $\mathrm{Cx} 46$ gap junction channel by placing negative charges close to the intracellular endings (see Fig. 9). This behaviour of the model ensues from the different diffusion properties of the ion species. However, according to the model this charge profile predicts outward rectification for a $\mathrm{Cx} 46$ hemichannel (data not shown), a property which contradicts with the experimental observations [23, 24]. Moreover, irrespective of the fixed charge distribution, the PNP-model does not show rectification for homotypic gap junction channels in the presence of solutions with small ions of similar diffusion coefficients, e.g. $\mathrm{K}^{+}$and $\mathrm{Cl}^{-}$(data not shown). While this behaviour seems to be consistent with two recent reports [17, 24], it conflicts with our own observations (R. Sakai, R. Weingart, unpublished results). The discrepancies between our measurements and PNP- simulations may arise from the fact that the application of the PNP-model to gap junction channels does not take into account the structural and electrical properties of the docking zone. Specifically, putative effects of the extracellular bulk potential on the potential profile and the conductive behaviour are not considered. Furthermore, a fit of our data required a pore radius of $5.3 \AA$ rather than the $4.75 \AA$ previously proposed for $\mathrm{Cx} 46$ gap junction channels [24]. This discrepancy may reflect the effects of hemichannel docking on channel conductance [24]. Using the channel parameters deduced from the $\mathrm{K}^{+}$aspartate ${ }^{-}$ solution data, PNP-modelling yielded the same solutiondependent ranking of $\gamma_{\mathrm{j} \text {,main }}$ as our experiments. However, while the values for the solutions containing aspartate ${ }^{-}$ were identical $\left(\mathrm{K}^{+}\right.$aspartate ${ }^{-}: 127$ vs. $127.5 \mathrm{pS}$; $\mathrm{TEA}^{+}$ aspartate ${ }^{-}: 66$ vs. $65.7 \mathrm{pS}$; see Table 3), they deviated for $\mathrm{Cl}^{-}$containing solutions (KCl: 157 vs. $212.7 \mathrm{pS}$; TEA ${ }^{+}$ $\mathrm{Cl}^{-}: 81$ vs. $108.8 \mathrm{pS}$ ). This suggests that each pipette solution is longing for another charge distribution. These considerations indicate that the PNP-model predicts some aspects of the electrical properties of gap junction channels, but not all.

\section{Temperature effects}

Elevation of temperature increased the conductances and accelerated the kinetics at both single- and multi-channel levels (see Figs. 13 and 14). With regard to single-channel

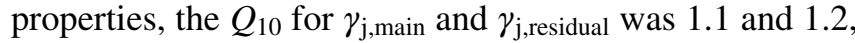
respectively (temperature range: $17-37{ }^{\circ} \mathrm{C}$ ). This is consistent with the view that ion transfer in the residual state is impaired slightly compared with the main state. Steric and/or electrical constrains may be responsible. The same conclusion has been drawn from studies on Cx30 and Cx40 channels [4, 28]. With regard to multichannel properties, increasing the temperature decreased $V_{\mathrm{j}, 0}$ and increased $g_{\mathrm{j}, \min }$ and $z$. The $Q_{10}$ values were 1.3 , 1.2 and 1.4, respectively, i.e. slightly above that for pure physical processes. The increase in $g_{\mathrm{j}, \min }$ is compatible with the increase in $\gamma_{\mathrm{j}}$. It may relate to an increase in $\sigma$ and conformational changes of the channel proteins. The latter may be responsible for the increase in $z$.

Significance for the physiological role of $\mathrm{Cx} 46$

The results presented yield a deeper insight into the properties of $\mathrm{Cx} 46$ channels. The unitary conductance is rather large. It suggests a considerable pore size, a property beneficial to the metabolism in the avascular lens. Early during cataractogenesis, the fibre cells of the lens swell and form pinhead opacities containing elevated levels of $\mathrm{Ca}^{2+}$ sufficient to close gap junction channels [10]. Rupture of the membrane of swollen fibre cells leads to depolarization of $V_{\mathrm{m}}$ creating a voltage drop between ruptured and intact cells, while the $\mathrm{Ca}^{2+}$ level increases in the damaged cells. As a result, $V_{\mathrm{j}}$ gating and $\mathrm{Ca}^{2+}$ gating of $\mathrm{Cx} 46$ channels begin to operate and may play a 
defensive role by restricting opacification to discrete regions.

Acknowledgements We thank D. Paul (Harvard Medical School, Boston, USA) for providing rat Cx46 cDNAs, B. Eisenberg and B. Burgess (Rush Medical School, Chicago, USA) for help with the PNP-model and W. Senn (University of Bern, Switzerland) for data analysis. This work was supported by the Swiss National Science Foundation (31-45554.95, 31-55297.98 and 31-67230.01 to R.W.), the Deutsche Forschungsgemeinschaft (SFB 284 to K.W.) and the Fonds der Chemischen Industrie (to K.W.).

\section{References}

1. Banach K, Weingart R (2000) Voltage gating of Cx43 gap junction channels involves fast and slow current transitions. Pflugers Arch 439:248-250

2. Beyer EC, Kistler J, Paul DL, Goodenough DA (1989) Antisera directed against connexin 43 peptides react with a $43-\mathrm{kD}$ protein localized to gap junctions in myocardium and other tissues. $\mathbf{J}$ Cell Biol 108:595-605

3. Bukauskas FF, Weingart R (1993) Voltage-dependent gating of single gap junction channels in an insect cell line. Temperature dependence of gap junction properties in neonatal rat heart cells. Pflugers Arch 423:133-139

4. Bukauskas FF, Elfgang C, Willecke K, Weingart R (1995) Biophysical properties of gap junction channels formed by mouse connexin40 in induced pairs of transfected human HeLa cells. Biophys J 68:2289-2298

5. Chanson M, Chandross KJ, Rook MB, Kessler JA, Spray DC (1993) Gating characteristics of a steeply voltage-dependent gap junction channel in rat Schwann cells. J Gen Physiol 102:925-946

6. Chen C, Okayama H (1987) High efficiency transformation of mammalian cells by plasmid DNA. Mol Cell Biol 7:2745-2753

7. Chen DP, Xu L, Tripathy A, Meissner G, Eisenberg B (1999). Selectivity and permeation in calcium release channel of cardiac muscle: alkali metal ions. Biophys J 76:1346-1366

8. Donaldson PJ, Roos M, Evans C, Beyer E, Kistler J (1994) Electrical properties of mammalian lens epithelial gap junction channels. Inv Ophthalm Vis Sci 35:3422-3428

9. Donaldson PJ, Dong Y, Roos M, Green C, Goodenough DA, Kistler J (1995) Changes in lens connexin expression lead to increased gap junctional voltage dependence and conductance. Am J Physiol 269:C590-C600

10. Duncan G, Williams M R, Riach RA (1994) Calcium, cell signalling and cataract. Progr Ret Eye Res 13:623-652

11. Ebihara L, Berthoud VM, Beyer EC (1995) Distinct behavior of connexin56 and connexin46 gap junctional channels can be predicted from the behavior of their hemi-gap-junctional channels. Biophys J 68:1796-1803

12. Goodenough DA (1992) The crystalline lens. A system networked by gap junctional intracellular communication. Semin Cell Biol 3:49-58

13. Harris AL, Spray DC, Bennett MVL (1981) Kinetic properties of a voltage-dependent junctional conductance. J Gen Physiol 77:95-117

14. Hopperstad MG, Srinivas M, Spray DC (2000) Properties of gap junction channels formed by $\mathrm{Cx} 46$ alone and in combination with Cx50. Biophys J 79:1954-1966

15. Horst M, Harth N, Hasilik A (1991) Biosynthesis of glycosylated human lysozyme mutants. J Biol Chem 266:13914-13919

16. Lal R, Arnsdorf MF (1992) Voltage-dependent gating and single-channel conductance of adult mammalian atrial gap junctions. Circ Res 71:737-743

17. Lu C, McMahon DG (1996) Gap junction channel gating at bass retinal electrical synapses. Vis Neurosci 13:1049-1057
18. McMahon DG, Brown DR (1994) Modulation of gap-junction channel gating at Zebrafish retinal electrical synapses. J Neurophysiol 72:2257-2268

19. Moreno AP, Laing JG, Beyer EC, Spray DC (1995) Properties of gap junction channels formed of connexin 45 endogenously expressed in human hepatoma (SKHep1) cells. Am J Physiol 268:C356-C365

20. Musil LS, Beyer EC, Goodenough DA (1990) Expression of the gap junction protein connexin43 in embryonic chick lens: molecular cloning, ultrastructual localization, and post-translational phosphorylation. J Membr Biol 116:163-175

21. Paul DL, Ebihara L, Takemoto LJ, Swenson KI, Goodenough DA (1991) Connexin46, a novel lens gap junction protein, induces voltage-gated currents in nonjunctional plasma membrane of Xenopus oocytes. J Cell Biol 115:1077-1089

22. Sakai R, Elfgang C, Willecke K, Weingart R (1998) Electrical properties of rat $\mathrm{Cx} 46$ gap junction channels studied in transfected HeLa cells (abstract). Pflugers Arch 435:R47

23. Trexler EB, Bennett MVL, Bargiello TA, Verselis VK (1996) Voltage gating and permeation in a gap junction hemichannel. Proc Natl Acad Sci USA 93:5836-5841

24. Trexler EB, Bukauskas FF, Kronengold J, Bargiello TA, Verselis VK (2000) The first extracellular loop domain is a major determinant of charge selectivity in connexin46 channels. Biophys J 79:3036-3051

25. Valiunas V, Weingart R (1997) Voltage gating and conductive properties of gap junction hemichannels studied in transfected HeLa cells. In: Proceedings of the 1997 International Gap Junction Conference, Key Largo, Florida, USA, July 12-17, 1997, p 97

26. Valiunas V, Weingart R (2000) Electrical properties of gap junction hemichannels identified in transfected HeLa cells. Pflugers Arch 440:366-379

27. Valiunas V, Bukauskas FF, Weingart R (1997) Conductances and selective permeability of connexin 43 gap junction channels examined in neonatal rat heart cells. Circ Res 80:708-719

28. Valiunas V, Manthey D, Vogel R, Willecke K, Weingart R (1999) Biophysical properties of mouse connexin30 gap junction channels in transfected human HeLa cells. J Physiol (Lond) 519:631-644

29. Valiunas V, Vogel R, Weingart R (2000) The kinetics of gap junction currents are sensitive to the ionic composition of the pipette solution. Pflugers Arch 440:835-842

30. Veenstra RD (1990) Voltage-dependent gating of gap junction channels in embryonic chick ventricular rat heart cells. Am J Physiol 258:C662-C672

31. Verheule S, van Kempen MJA, Postma S, Rook MB, Jongsma HJ (2001) Gap junctions in the rabbit sinoatrial node. Am J Physiol 280:H2103-H2115

32. Verselis VK, Trexler EB, Bukauskas FF (2000) Connexin hemichannels and cell-cell channels: comparison of properties. Braz J Med Biol Res 33:379-389

33. Vogel R, Weingart R (1997) Mathematical model of vertebrate gap junctions derived from electrical measurements on homotypic and heterotypic channels. J Physiol (Lond) 510:177-189

34. Wang H-Z, Li J, Lemanski LF, Veenstra RD (1992) gating of mammalian cardiac gap junction channels by transjunctional voltage. Biophys J 63:139-151

35. Wilders R, Jongsma HJ (1992) Limitations of the dual voltageclamp method in assaying conductance and kinetics of gap junction channels. Biophys J 63:942-953

36. White TW, Bruzzone R, Goodenough DA, Paul DL (1992) Mouse Cx50, a functional membrane of the connexin family of gap junction proteins, is the lens fiber protein MP70. Mol Biol Cell 3:711-720

37. White TW, Bruzzone R, Wolfram S, Paul DL, Goodenough DA (1994) Selective interaction among the multiple connexin proteins expressed in vertebrate lens: The second extracellular domain is a determinant of compatibility between connexins. J Cell Biol 125:879-892 